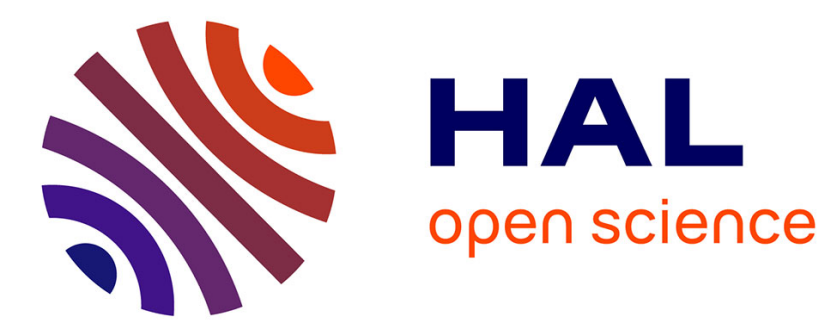

\title{
Common bats are more abundant within Natura 2000 areas
}

\author{
Christian Kerbiriou, Clémentine Azam, Julien Touroult, Julie Marmet, \\ Jean-François Julien, Vincent Pellissier
}

\section{- To cite this version:}

Christian Kerbiriou, Clémentine Azam, Julien Touroult, Julie Marmet, Jean-François Julien, et al.. Common bats are more abundant within Natura 2000 areas. Biological Conservation, 2018, 217, pp.66-74. 10.1016/j.biocon.2017.10.029 . hal-02554194

\section{HAL Id: hal-02554194 https://hal.science/hal-02554194}

Submitted on 25 Apr 2020

HAL is a multi-disciplinary open access archive for the deposit and dissemination of scientific research documents, whether they are published or not. The documents may come from teaching and research institutions in France or abroad, or from public or private research centers.
L'archive ouverte pluridisciplinaire HAL, est destinée au dépôt et à la diffusion de documents scientifiques de niveau recherche, publiés ou non, émanant des établissements d'enseignement et de recherche français ou étrangers, des laboratoires publics ou privés. 
1 Common bats are more abundant within Natura 2000 areas

2

3 Christian Kerbiriou ${ }^{1,2 *}$, Clémentine Azam $^{1}$, Julien Touroult ${ }^{3}$, Julie Marmet ${ }^{1,3}$, Jean-François

4 Julien $^{1}$, Vincent Pellissier ${ }^{1,3,4}$

5

$6 \quad{ }^{1}$ Muséum National d'Histoire Naturelle, Centre d'Ecologie et des Sciences de la

7 Conservation - UMR 7204 MNHN-CNRS-UPMC, 55 rue Buffon, 75005 Paris, France.

$8{ }^{2}$ Muséum National d'Histoire Naturelle, Station de Biologie Marine, 29900 Concarneau,

9 France.

$10 \quad{ }^{3}$ Muséum National d'Histoire Naturelle, UMS 2006 MNHN-CNRS-AFB Centre d'expertise et 11 de données sur la nature, 36 rue Geoffroy Saint-Hilaire, 75005 Paris, France.

$12{ }^{4}$ Section for Ecoinformatics and Biodiversity, Department of Bioscience, Aarhus University,

13 Ny Munkegade 114, 8000 Aarhus C, Denmark.

14

15 * Corresponding author: christian.kerbiriou@mnhn.fr

16 Tel: +0033 (0) 140793831

17 
The Natura 2000 network is the largest conservation effort in Europe. However, despite the known importance of conserving common and widespread biodiversity, criteria used to designate a Natura 2000 site are oriented toward rare and/or emblematic biodiversity. In this study, we took advantage of the fact that the management of Natura 2000 is just beginning to assess whether the five most common bat (Chiroptera) species and one genus in France exhibit a greater relative abundance within rather than outside Natura 2000 boundaries, and three bats communities index: total relative abundance, species richness, Community Habitat specialization index. We model the relative abundance of each taxa and indices using data from a nationwide volunteer-based acoustic survey. We found that three of the six taxa studied exhibit greater relative abundance within Natura 2000 sites (this increase is noteworthy for E. serotinus (x 2.1) and Myotis $\operatorname{ssp}$ (x 3.6)). We also provide evidence that total relative abundance of bat activity and richness are globally higher in Natura 2000 sites (respectively $+24 \%$ and $+14 \%$ ) and on average communities are more specialized within Natura 2000 sites. In addition, when the effect of Natura 2000 is adjusted to the main land use types, a significant positive effect of Natura 2000 remains for most metrics. The positive Natura 2000 effect appears relatively small compared to the main land use pressure: intensive agriculture and artificial light at night. However, Natura 2000 has a comparable sized effect as habitat widely recognized as having a positive impact on bats, such as streams.

Keywords: bats relative abundance, common biodiversity, Natura 2000; mean trait community, 


\section{Introduction}

Among the approaches employed to preserve biodiversity, the establishment and management of statutory protected areas are widely regarded as key strategies (Jackson et al., 2007). This classic protection approach is based on the principle that the designation of areas affords the protection of habitats, species and/or populations that are threatened elsewhere (Gaston et al., 2008). In addition to National Nature Reserves, National Parks and Regional Parks that are designated by state members, the European Union (EU) has coordinated the Natura 2000 network. This network, which is the most important coordinated supra-national conservation effort at the world level (Evans, 2012), aims at maintaining remarkable biodiversity through the sustainable use of natural resources by establishing a network of areas that must maintain a range of habitat types and wildlife species in a "favorable conservation status" (European Commission, 2000). Over the last 25 years, the EU has built a vast network that represents $18 \%$ of the EU's land area (see Supplementary Material S1). In France, this network represents $12.5 \%$ of the continental territory. The main objectives of conservation and restoration are stated at the local scale in the Natura 2000 management plan and the French Natura 2000 areas are mainly managed through contracts between land owners and the state. Agri-Environmental Schemes (Caps) are applied in agricultural land, whereas ones in nonagricultural land may receive incentives for measures that favor conservation of biodiversity. Although such actions are defined in each management plan, the field management of Natura 2000 has only recently begun (by 2005 only $20 \%$ of Natura 2000 sites had endorsed their management plan (Maresca et al. 2006) and by 2012 nearly 73\%, and establishment of new plan has been slow since 2005, Debain, 2011).

Identification of the Natura 2000 areas is now broadly completed (Note however, that Member States can regularly add new sites), and attention is turning toward assessing whether 
the Natura 2000 network effectively protects species and habitats (Martínez et al., 2006). As Kliejn \& van Zuijlen (2004) stated, the observed differences between protected and nonprotected areas may result from either the initial state of biodiversity ('designation effect', assessed through a comparison of the biodiversity inside and outside the N2000 sites) or from the protection efficiency per se ('protection effect', which involve the comparison of the state of biodiversity before and after the designation of N2000 sites). Thus, the French case provides a good opportunity to assess the first of these effects ('designation effect'), i.e., differences in the initial biodiversity state between areas inside and outside the Natura 2000 network, because within the studied period half of Natura 2000 sites had just endorsed their management plan and thus, management actions were too recent to already have an effect on the state of the biodiversity.

A growing number of studies have been carried out to evaluate the effectiveness of the Natura 2000 network for threatened species (Trochet \& Schmeller, 2013) or species or habitats targeted by Natura 2000 (i.e. listed under priority Annex, vegetation: Rosati et al., 2008, bats: Lisón et al., 2015). Some studies like Donald et al., (2007) have found a strong positive correlation between Member States' percentage land cover of Natura 2000 and population trends of species targeted by the EU Birds Directive (EC79/409).

Common biodiversity is of particular importance in ecosystem functioning (Smith \& Knapp, 2003; Solan et al., 2004), but there are few protection measures directed toward common species. While some common species are legally protected (common bats are listed in Annex IV Habitat Directive), there are no protected areas designated specifically at the benefice of these species, as protected areas are not considered as the appropriate tool for these kinds of species (Gaston 2011). Surprisingly, few studies (Devictor et al., 2007, Pellissier et al., 2013) have assessed the importance of classical protection measures on common bird biodiversity, 
showing that common bird species have actually benefited from protection measures directed toward other target species.

In addition, among the studies focused on the evaluation of the designation effectiveness of the Natura 2000 network, the overwhelming majority of them were gap analyses based on species distribution (vertebrates: Kukkala et al., 2016, invertebrates: Sánchez-Fernández et al., 2013, amphibians and reptiles: Abellán \& Sánchez-Fernández, 2015, Bat: Lisón et al., 2013, 2015, all vertebrates: Kukkala et al., 2016, all taxa: Trochet \& Schmeller, 2013), while ecosystem functioning also requires the consideration of species abundance and community scale (Loreau et al., 2001). In addition, a review of studies dealing with Natura 2000 perform by Orlikowska et al., (2016) concluded that a majority of studies were performed in singe Natura 2000 site, and suggest that more studies will need to encompass large spatial scale. Monitoring based on skilled volunteers counting common species (birds, amphibians and reptiles, mammals, butterflies and plants) has already provided reliable abundance data and unbiased results (Genet \& Sargent, 2003; Schmeller et al., 2009) regarding the effects of climate change (Julliard et al., 2004) or the effectiveness of protection measures (Devictor et al., 2007; Jiguet, 2011). Using volunteer bat-workers, the French National History Museum initiated a bat monitoring program (Vigie Nature 2011) to assess the current state and trends of common bat population in France (Kerbiriou et al., 2010). Most of the European bat populations, including common species, have experienced dramatic declines in the last century (Voigt \& Kingston, 2016) mostly because of the habitat loss and fragmentation induced by agricultural intensification (Wickramasinghe et al., 2004, Azam et al., 2016), urbanization (Kurta \& Teramino, 1992; Azam et al., 2016) and intensive forest management (O’Donnell, 2000)

Using the French bat monitoring data, we tested, mostly on non-target species, whether the relative abundance of species or community metrics (total relative abundance, richness and 
115 habitat community specialization) were influenced by the Natura 2000 network. This test of

116 Natura 2000 designation effect was achieved through two analyses, one comparing bat

117 activities within and outside Natura 2000 sites and a second approach, in which we assessed

118 the influence of Natura 2000 areas controlling for the main land uses and at different

119 landscape scales. Higher relative abundance within Natura 2000 is expected if the Natura

1202000 areas exhibit a 'designation effect', i.e., the Natura 2000 areas are high-value areas for

121 common species.

\section{MATERIAL AND METHODS}

\section{Car transect survey}

125 The data were provided by the French bat monitoring program (FBMP)

126 (http://vigienature.mnhn.fr/page/vigie-chiro), a citizen-science program running since 2006 and coordinated by the French National Museum of Natural History (NMNH). Volunteers recorded bat activity while driving at a constant low-speed $(25 \pm 5 \mathrm{~km} / \mathrm{h})$ along a $30 \mathrm{~km}$ road circuit within a $10 \mathrm{~km}$ buffer around their home. Surveyors were asked to design their road

130 circuit so that it proportionally crossed, as much as possible, the different land-cover types

131 and it remained on low-traffic roads for security reasons. After final validation of the circuit

132 outline, program coordinators randomly selected the starting point of the survey. Each circuit

133 was then divided into 10 road transects (length of transect $2 \mathrm{~km}$ ) where bats were recorded,

134 separated by $1 \mathrm{~km}$ road portions where recording was not carried out (Supplementary

135 Material 1). Such a sampling design resulted in a survey of habitats that are quite

136 representative of French land cover (see Supplementary Material 1). We used data from

137 surveys carried out every year from the 15 th of June to the 31 st of July, corresponding to a

138 seasonal peak in bat activity, a period during which bat females typically give birth to and

139 feed their offspring. Surveys started $30 \mathrm{~min}$ after sunset and lasted approximately $1.5 \mathrm{~h}$ during 
140 the period of bat activity, and were only carried out when weather conditions were favorable

141 (i.e., no rain, low wind speed of $<7 \mathrm{~m} / \mathrm{s}$, temperature $>12{ }^{\circ} \mathrm{C}$ ). This sampling design is quite

142 similar to that used by many European bat monitoring schemes (Roche et al., 2011). At total

143 of 160 different car-based circuits were surveyed during the study period (2006 to 2013)

144 (Supplementary Material 1), corresponding to 1608 independent 2-km transects, and each

145 circuit was sampled an average of $2.4 \pm 0.04$ times.

\section{Biological data}

148 Along transects, volunteer surveyors recorded bat echolocation calls with ultrasound detectors

149 connected to digital recorder (See Supplementary Material 1 for more details about technical

150 points). Once the recording was performed, the observers were asked to identify the species

151 detected in each transect using Syrinx software version 2.6 (Burt, 2006) and spectrogram

152 analyses. The majority of volunteers involved in the bat monitoring participated in training

153 courses organized by the MNHN, allowing a high level of homogeneity of the identification

154 criteria. In a second step, the identifications were validated by MNHN experts. Bat calls were

155 identified at the species level except for species of the Myotis genus. Due to the lack of

156 general consensus on the acoustic criteria to distinguish some Myotis species and some

157 overlap between their acoustic repertoires, it was not possible to assign the exact species with

158 certainty for all calls; thus, we constructed a Myotis spp group (see Supplementary Material

$159 \mathrm{~S} 1)$. Note that according to their foraging trait, bat species of the genus Myotis within the

160 study area could be considered as a group of slow-flying species including mainly "narrow

161 space gleaning foragers" and "trawling bat" compared to the group of the fast-flying species

162 including mainly "open or space aerial foragers" (i.e. Pipistrellus spp, Eptesicus serotinus and

163 Nyctalus spp) species that mainly hunt for airbone prey in open space or in edge space

164 (Dezinger \& Schnitzler, 2013). Indeed, an analysis based on a group composed of species of 
165 the same genus (i.e. Myotis spp) could lead to non-significant results due to opposite effects

166 among species included such a group. However, when significant effects are detected, this

167 involves that at least one species of this group was enough sensitive to the variable tested.

168 As it is impossible to distinguish individual bats from echolocation calls. For this reason, we

169 produced for each 2-km road transect sampled, and for each year, a bat activity index (name

170 hereafter "relative abundance") defined as a number of bat pass per species (a bat pass

171 corresponds to a trigger of the bat detector in time expansion, see Supplementary Material 1).

172 The response variables were (i) species relative abundance (i.e. number of bat passes); (ii)

173 total relative abundance (this measure was corrected by species distance of detection

174 (Barataud 2015), species bat activity was weighted by the multiplicative inverse of the

175 distance of detection squared, thus a species with a great distance of detection contributes less

176 for total relative abundance than a species with a small distance of detection; (iii) species

177 richness, (iv) Community Habitat specialization index (CSI). CSI is a mean trait community

178 index based on weighted average of habitat specialization of each species present in the

179 community, for more detail on CSI calculation see Supplementary Material 2. The recorded

180 species are all protected species listed in annex IV of the Habitats Directive but they are not

181 target species of the Natura 2000 network (non annex II species, except within the group

182 Myotis spp which may include some species included in annex II but mainly in very slight

183 proportion in our data collection see Supplementary Material 1, Table S1-6).

185 Landscape and Natura 2000 data

186 Around each of the 1608 transects (i.e. the $2-\mathrm{km}$ road portions), we generated a set of

187 landscape variables using QGIS 2.2. Because the landscape effect on bat activity could

188 change according to the spatial scale considered (Grindal \& Brigham, 1999; Lacoeuilhe et al.,

189 2016) we calculated these variables at 4 different buffers of 200, 500, 700 and $1000 \mathrm{~m}$. At 
1000 m landscape scale, there was $25 \%$ overlap between nearby transects belonging to a

191 same road circuit. However, this still allowed the measurement of variation in landscape characteristics within the same road circuit. However, we could not extend the analyses into

193 larger landscape scales, because the overlapping rate between transect buffers would exceed

$19450 \%$. We assessed the proportion of the Natura 2000 areas included in each buffer (shapes

195 were provided by the Muséum national d'Histoire naturelle (http://inpn.mnhn.fr, see

196 Supplementary Material 3). Sites designated for birds (Special Protection Areas, SPA) and/or

197 Habitats directive (Sites of Community Importance, SCI) were considered together as the

198 evaluation deals with the whole network designation effect on non-target bat biodiversity.

199 Note that analyses at the level of each directive (SCI and SPA) did not reveal any obvious

200 difference with the analysis performed at the level of Natura 2000 sites (both together), see

201 Supplementary Material 5, Table S5-3 \& S5-4.

202 We also calculated seven land use variables within each buffer, (i) the proportion of intensive

203 agriculture (Inten. Agri., Code 2.1; CORINE Land Cover, including irrigated and non-

204 irrigated arable land such as cereals, leguminous and forage crops.) within each buffer

205 because they represent a major land use pressure for bats (Azam et al., 2016); (ii) the

206 proportion of heterogeneous agriculture (Heter. agri.), defined as areas with a complex

207 mosaic of annual and permanent cultures and semi-natural habitats (Code 2.4; CORINE Land

208 Cover); (iii) the proportion of deciduous and mixed forests (Forests, Code 3.1; CORINE Land

209 Cover) as they were commonly represented in our buffers and were known to influence bat

210 activity at a landscape scale (Boughey et al., 2011; Frey-Ehrenbold et al., 2013;); (iv) the

211 proportion of open habitat (Open habitat, code 231 and 32 CORINE Land Cover; (v) the total

212 length of streams and water sources (Streams, IGN/2012) because numerous studies have

213 identified aquatic habitat as a favorable where abundance of bat is high (Rainho \& Palmeirim

214 2011; Russo \& Jones 2003, Salvarina 2016); (vi) the total length of roads (Roads, IGN/2012) 
within each buffer because effect of road network can be considered as a land use pressure,

216 especially regarding landscape connectivity. However, this pressure could not accurately be

217 tested in our study because transects were mostly located in areas with secondary low-traffic

218 roads, therefore, we only took into account the total length of roads as a potential confounding

219 factor of the urbanization. In addition, roads often included hedgerows, which could have a

220 positive effect on bat activity (Verboom \& Huitema, 1997; Lacoeuilhe et al., 2016); and (vii)

221 artificial light at night $(A L A N)$ defined as the radiant flux (i.e., radiant power) reflected or

222 emitted by a given surface., (see supplementary material 4 for details on the computation of

223 this variable). We used light pollution data as a proxy of the urbanization process as it

224 encompasses both the effects of impervious surfaces and urban-induced pollution that

225 propagates beyond urban areas (Azam et al. 2016)

Representativeness of habitats and land uses sampled in the French bat monitoring

\section{program}

229 This survey protocol resulted in the collection of data along roads chosen by volunteers,

230 which may introduce a bias in the habitat sampling. Preliminary analysis have underlined that

231 the choice of the circuit performed by volunteers plus the randomization introduced by the

232 MNHN limited the bias in habitat representativeness at local and national scales (see

233 Supplementary Material S1, Table S1-1). Because buildings tend to be concentrated along

234 road networks, the main bias observed was with regard to urban areas and, in particular,

235 impervious areas, which comprises 5\% of France. However, our survey included $11 \%$ at a

$236200 \mathrm{~m}$ landscape scale, but note that this bias decreases when landscape scale take into

237 account increase ( $6 \%$ of impervious areas in buffer of $1000 \mathrm{~m}$ size). We did not detect any

238 bias for the representativeness of Natura 2000 regardless of the spatial scale considered (see

239 Supplementary Material S1, Table S1-1) 
240 A second expected type of bias concerns the presence of hedgerows or forest edges along the 241 roads, which could result in an overall increase in insect availability, as aerial insects tend to 242 concentrate on the lee side of hedgerows (e.g., Lewis \& Stephenson, 1966). Therefore, the 243 observation of an over-representation of linear elements in the Natura 2000 areas could 244 indicate a biased prediction of bat activity. Indeed, some bat species tend to forage along 245 these linear elements (Verboom \& Huitema, 1997) and fly along such features when 246 commuting from roosts to foraging areas (Limpens \& Kapteyn, 1991). Surprisingly, we 247 detected a slight trend for there to be fewer hedgerows within the Natura 2000 area (See 248 Supplementary Material 1, table S1-2, table S1-3). In general, habitats along roads are not a 249 random subset of all the available habitats in the wider countryside. In fact, some rare habitats 250 are most likely underrepresented; in addition, with such road sampling, we mainly sampled 251 edge habitats instead of core habitats, which could result in a bias for some Myotis species 252 that preferentially forage in closed environments (see Russo \& Jones, 2003; Rainho, 2007) but 253 is most likely to not a major problem for the five other species studied here, which do not 254 select closed environments (Russ \& Montgomery, 2002; Rainho, 2007).

\section{Statistical analyses}

\section{$257 \quad$ Model building}

258 Initially, we assessed if bat activity measures along transects differ from site to site within or 259 outside a Natura 2000 site (Natura 2000_PA, a binomial variable) using Generalized Linear 260 Mixed Model (GLMM). The response variable was either species relative abundance ( $\mathrm{n}=6$ 261 taxa) or bat community metrics (total relative abundance, richness or CSI). We add as covariables the date of survey, the wind speed, the time elapsed after sunset and the temperature

263 because we assumed that bat activity might be affected by weather conditions (Ciechanowski 264 et al., 2007). Note however, that the protocol is performed only when weather conditions are 
generally favorable (see Supplementary Material 1, Table S1-1). As these co-variables might

266 have non-linear effects on these co-variables, we included quadratic form terms for the variables (see Supplementary Material 5, S5-1). According to the hierarchical structure of our sampling design (same sites were sampled year to year), we treated site and year as random effects (Zuur et al., 2009). Thus, our models were structured in the following way:

[bat activity] Natura 2000_PA + date of survey + wind speed + minutes after sunset + temperature $+1 \mid$ year $+1 \mid$ site

\section{Check of assumptions of GLMM}

275 Before performing our models, we systematically evaluated the correlations among 276 explanatory variables using Spearman's rho for quantitative variables (Crawley, 2009) to detect obvious correlation (See Supplementary Material 5). Secondly, we performed varianceinflation factors (VIF) on each model (Fox \& Monette 1992); all variables had VIF<2 indicating no problem of multicollinearity in the explanatory variables of our models.

280 Close points (even if they differ from habitat) are likely to have a similar bat population 281 density due to similar climatic conditions or large-scale landscape compositions and could 282 therefore imply spatial autocorrelation. Thus, we performed a variogram to observe if correlation between neighbors falls off with distance. When we detected such patterns in our data, we added in our GLMM an autocovariate (i.e., a distance-weighted function of neighboring response values; Dormann et al. 2007) with the autocov dist function in $\mathrm{R}$

286 (package spdep, Bivand R. et al. 2011) to account for spatial autocorrelation. 
areas at a landscape scale on bat activity taking into account the main land uses. Thus, in

291 addition to Natura 2000 areas, we included seven other landscape variables as fixed effects.

292 These analyses were performed at four scales: 200, 500, 700 and $1000 \mathrm{~m}$. The fixed effects

293 were centered and standardized so that the regression coefficients were comparable in 294 magnitude and their effects were biologically interpretable (Schielzeth 2010). Thus, our 295 models were structured in the following way:

297 [bat activity] Natura $2000+$ Inten. agri + Heter. agri. + Forests + Open habitat + Roads + 298 Streams + ALAN + date of survey + wind speed + minutes after sunset + temperature $+1 \mid$ year $299+1 \mid$ site

301 According to the nature of the response variable (bat count) and potential over-dispersion, we 302 chose the best error distribution among Poisson, a negative binomial distribution and zero inflation models with a negative binomial or Poisson error distribution (Zuur et al. 2009), and when abundance modelling did not fit well (i.e. Myotis ssp), we transformed the response variable (i.e. bat relative abundance) into a presence/absence variable and used a binomial error distribution, (see Supplementary Material 5, Table S5-1).

\section{RESULTS}

The survey recorded 23164 bat passes, on which analysis was conducted on the most 310 commonly recorded species: Pipistrellus pipistrellus $(\mathrm{n}=14967)$, Eptesicus serotinus $(\mathrm{n}=$ 311 2614), Pipistrellus kuhlii $(\mathrm{n}=2318)$, (note that even after checking the identifications, we extrapolated that $8 \%$ of $P$. kuhlii calls are not entirely certain and could include $P$. nathusius

313 calls), See Table S1 for details), Nyctalus leisleri $(\mathrm{n}=1999)$, Nyctalus noctula $(755)$ and 314 Myotis spp. (261). The first species represented 65\% of the dataset. 
315 Without adjusting Natura 2000 effect to take landscape composition into account, $P$. 316 pipistrellus and E. serotinus exhibited greater relative abundance within Natura 2000 than 317 outside, and Myotis spp. have a greater probability to be recorded within Natura 2000, while 318 we detected no significant effect for the three other species (Table 1). In addition, we detected 319 a greater relative abundance, a greater richness and communities are more specialized within 320 Natura 2000 than outside (Table 1).

321 When taking into account the main land uses within landscape and assessing the effect of the amount of Natura 2000 (i.e. areas of Natura 2000 in the neighbor of the sample site and not just being in a site or off site), we detected a similar relationship to the first set of analyses. Among the six species studied, we were able to detect a positive influence of Natura 2000 in the area bordering transects for P. pipistrellus, E. serotinus and Myotis spp. (Table 2). However, the detection of significant effects was scale dependent, and mainly detected at a small spatial scale (i.e. at $200 \mathrm{~m}$, except for Myotis spp). In addition, total bat activity and community bat specialization were positively influenced by Natura 2000 areas, whereas no effect was detected for richness (Table 2). Again, we detected more significant effects at a smaller spatial scale.

331 The proportion of intensive agriculture had a significant negative effect on all species (except N. noctula). We found same results for all bat community metrics whatever the landscape scale considered. Artificial light at night, heterogeneous agriculture and open habitat, when

334 significant, had a negative effect, whereas streams mainly had significant positive effect

335 (except for E. serotinus) but again the effect was scale dependent and varied among species or 336 bat community metrics (Table 2, Fig. 1). Forest effects depend of bat activities measured: for example $P$. pipistrellus was positively influenced by the proportion of forest while $N$. lesileri was negatively influenced, total bat relative abundance positively influenced, while richness and community specialization were negatively influenced by forest (Table 2, Fig. 1). 


\section{DISCUSSION}

344 This paper provides evidence that bat activity is globally higher in Natura 2000 sites (+24\%;).

345 Three (P. pipistrellus, E. serotinus, Myotis spp) of the six species/genera studied exhibit 346 greater relative abundance in Natura 2000 sites (this increase is noteworthy for E. serotinus (x 347 2.1) and Myotis ssp (x 3.6)) and note that no significant negative effect was detected. The 348 result for Myotis spp must be taken with caution; it did not imply that all species of this genus 349 exhibit a similar pattern, but at least one species exhibits a greater bat activity in Natura 2000 350 sites. We also detected a greater richness in Natura 2000 sites $(+14 \%)$. Finally, the bat 351 community specialization, a mean trait community index, is greater in Natura 2000 sites $352(+9 \%)$.

353 In a second step, we evaluated if this Natura 2000 effect was consistent when, in the 354 neighborhood of the survey, the proportion of Natura 2000 was adjusted to the land uses. For P. pipistrellus, E. serotinus and Myotis spp, the increase of Natura 2000 in the surrounding 356 area positively influenced their activity but the effect was spatial scale dependent. Similarly, 357 bat community specialization, increased when Natura 2000 areas increased in qrea 358 surrounding transects. However, we did not detect any effect of the proportion of Natura 2000 359 areas in the surrounding of transects on species richness. Note that this latter non-detection is 360 possibly linked to the nature of data collected (small sequence of acoustic recordings) which 361 currently did not allow species identification within the Myotis group, while this group is very 362 rich in the region considered (39\% of the French species, TAXREF, Gargominy et al., 2016-). 363 With the recent arrival on the market of new generation of bat detector-recorders, we could 364 consider recording throughout the entire night (see Newson et al., 2015) and thus expect an 
increase in the probability of contacting and identifying Myotis species. A protocol using this new technology is under development by the FBMP (Bas et al., 2017), thus a more accurate assessment of Natura 2000 effect on richness could be expected in the future. land use pressure: intensive agriculture and to a lesser extent heterogeneous agriculture (while this category is known to include more extensive agriculture practice) and light pollution

371 (ALAN) all of them have a deep negative impact. They impact not only the abundance of populations but also the structure of communities, leading to less rich and more generalist communities, thus contributing to a biotic homogenization process (McKinney, 2006, Karp et al., 2012). These drivers are known to impact negatively bats (Wickramasinghe et al., 2004; Azam et al. 2016) and more broadly biodiversity, both rare and endangered species (Maxwell et al., 2016) as the common species and (plants: moth: Conrad et al. 2006; butterflies: Van Dyck et al. 2009; bees: Kosior et al., 2007; birds: Donald. 2001) and contribute to large scale biotic homogenization (Le Viol et al. 2012). The negative effect of open habitat is mainly due to the requirement of the species studied to avoid large open habitat (Verboom, \& Spoelstra, 1999) and select wooded edge, woodland or aquatic habitat (Walsh \& Harris, 1996). The

381 positive effect of streams is (although detected for many species or bat community measures) 382 in accordance with many studies see the review perform by Salvarina (2016). The contrasting effect of forest areas on the species studied (dominated by aerial hawking species), positive effect on total relative abundance, while negative effect on richness and community specialization, seem to indicate that these land uses, when adjusted for the effect of Natura 386 2000, does not have a broad effect. Zehetmair et al., (2015), in a sample of European beech 387 forest, found that bat activity did not differ significantly between the Natura 2000 and non388 Natura 2000 forest on paired comparison of stands with same structural attributes. They concluded that the current management of the Natura 2000 beech forests is almost identical to 
that of non-Natura 2000 commercial forests, and thus, the Natura 2000 status has not led to an

391 increase of bat-relevant habitat variables yet. By comparing similar beech forest habitats,

392 Zehetmair et al., (2015) may have missed the fact that the Natura 2000 network may also

393 include a higher proportion of high quality habitats than usual non Natura 2000 forests. On

394 the contrary, our study design (including a great number of sites and, in turn, a wide range of

395 forest types) enables us to test for a more global Natura 2000 designation effect, which

396 remains even after taking landscape variables into account.

397 When the road effect is detected, it is surprisingly positive and appears to invalidate this

398 landscape variable as a pressure on bat foraging connectivity. Lisón \& Sánchez-Fernández

399 (2017) found that the roadless areas are not significant for the localization of bat hotspots. It

400 should be noted however, that we could not test accurately a "road effect" because our

401 sampling is not representative of national road network: due to security, and transects were

402

403

404

405

406

407

408

409

410

411

412

413

414 mostly located in areas with secondary low-traffic roads. Thus, within this biased sample, we probably detected an effect of availability of hedgerows along roads, where hedgerows are positively selected for by bats (Lacoeuilhe et al., 2016). The increase in relative abundance and degree of specialization may appear limited compared to the negative effect of intensive agriculture (respectively lower by a factor 6 and 2, Table 2). However, it is still notable that for common, widely distributed species, that there is still a Natura 2000 effect, after we control for land use variables like streams that are known to have a positive influence on bats (Salvarina, 2016).

It appears that the areas designated as Natura 2000 areas exhibit a 'designation effect' and providing evidence that such areas are most likely to be of better quality for bats with regard to their foraging activity. Similar results have been found by Lisón et al., (2015) in Spain, a study involving bat distribution and not bat abundance. Indeed, the Natura 2000 areas contain less intensive agriculture areas (Supplementary material Table S1-3) and more semi- 
natural areas and harbor more common biodiversity than non-Natura 2000 areas (Pellissier $e t$

416 al., 2013). This non-random habitat composition of Natura 2000 sites is part of the raw

417 "designation effect" of this network. Interestingly, when this habitat "bias" is partially taken

418 into account because the effect of Natura 2000 was adjusted to the main land use types, a

419 significant positive effect of Natura 2000 remains for most metrics. One possible

420 interpretation is that Natura 2000 have, on average, better structural and more micro-habitats

421 features or food webs important for bats than the same broad habitat types outside the

422 network.

\section{Scale and time effect}

When looking at the influence of spatial scale, the positive effect of Natura 2000 tends to be more significant at a smaller scale (i.e. $200 \mathrm{~m}$ ) while some land uses variables remain significant whatever the spatial scale considered (i.e. intensive agriculture, ALAN). This finding seems to indicate that Natura 2000 areas do not yet enhance adjacent areas at a large scale for common bats. However, a theoretically and empirically demonstrated reserve effect is the spillover of species richness and community complexity that highlights the important

431 benefit for biodiversity and ecosystems of establishing reserve areas (Roberts et al. 2001, 432 Russ \& Alcala, 2011). However, many studies have underlined that reserves could enhance 433 adjacent areas, but that age matters (Claudet et al., 2008, Russ \& Alcala, 2011). It should be 434 emphasized that the purpose of this paper is not to assess the efficiency of the management 435 measures actually occurring in the Natura 2000 areas; here we only assess a designation 436 effect. Indeed, management is probably too recent to be able to produce measurable effects, 437 because during the period studied (2006-2013) only 53\% of Natura 2000 sites had endorsed 438 their management plan, and moreover $69 \%$ of recordings were collected between 2006 and 4392009 (see Supplementary Material 1, Fig S1-1). We hypothesize that effect of Natura 2000 at 
440 large landscape scale should become more significant in the future with the effects of Natura

4412000 sites management and the implementation and green infrastructure policies, which aim

442 to connect patches of protected areas. Future research should now focus on comparing

443 biodiversity state before and after the designation of N2000 sites (see Lisón \& Sánchez-

444 Fernández, 2017), especially since conservation policy may moderate land-cover

445 transformation (Kallimanis et al., 2015).

\section{Car-based bat survey and policy implications}

The French bat monitoring program has proven to be a useful tool for evaluating the Natura 2000 network owing to its large spatial coverage and its standardized monitoring based on

volunteers. This finding emphasizes that public participation in scientific research is a promising approach that can significantly help scientists to address questions relating to biodiversity, as suggested by Bell et al., (2008) and Couvet et al., (2008). Volunteer-based monitoring is likely to have high resilience (Couvet et al., 2008), which is key to maintaining the monitoring program over time and, thus, providing extended time-series (Battersby, 2010). However, questions can be raised about more efficient ways to monitor biodiversity of a protected network, between surveying rarer species and habitats or to survey more common and widespread elements not targeted during the designation process. Indeed, rare species (due to lower abundance, lower detection, or their specialization to particular habitats) need focused sampling (Barlow et al., 2015). From a financial point of view, it should be noted that

460 the monitoring of common species does not involve funds dedicated to Natura 2000 surveys.

\section{Conclusion and conservation implications}


II), despite the fact that they benefit from a strict protection regime, they are not target species

466 for the designation of Natura 2000 areas. In addition, in the meta analysis performed in Spain,

467 Lisón et al., (2017) found that bats were not "emblematic" species for the managers,

468 especially the bat species of Annex IV. However, they remain policy relevant because they

469 are species of European concern and it is a highly valuable feature the Natura 2000 network

470 benefits common biodiversity. This result is congruent with many studies that assert that the

471 establishment and management of statutory protected areas are widely regarded as key

472 strategies and efficient tool for safeguarding key biodiversity areas (Jackson et al., 2009;

473 Watson et al., 2014). Although gap analysis have clearly demonstrated that the global

474 protected area network is still far from complete for encompassing broader biodiversity

475 (Rodrigues et al., 2004), our results suggest that Natura 2000 is able to encompass non-

476 targeted species, at higher level of relative abundance than outside the same landscapes. As

477 this network is the most important conservation effort in Europe (Evans, 2012), it is important

478 to recognize that its biodiversity coverage extends beyond the rare or threatened targeted

479 species and habitats and potentially promote management measures towards this more

480 common part of biodiversity and its functional role.

481 Additionally, most of the Natura 2000 areas designated for the protection of bat

482 species are limited to roosting sites and immediate surroundings. Indeed, for species with a

483 complex life cycle, reproduction is most often considered the most important part of the cycle,

484 and, thus, the protection of reproduction sites is emphasized (Stebbings, 1988). However,

485 whilst sites for bat reproduction are restricted in space, they have a large foraging territory,

486 even during reproduction (Stebbings, 1988). Therefore, protecting hunting territories, which

487 can be quite large and far from roosting sites, is of prime importance from a conservation

488 point of view (Vaughan et al., 1997). In this study, we assessed the influence of Natura 2000

489 areas on measures of foraging activity for six common Chiroptera species and three measures 
of community. Given the trophic level occupied by all the Chiroptera species in Europe (top

491 predators), the implications of our results may extend beyond the taxa considered and have important implications for the conservation of biodiversity as a whole.

493

\section{Acknowledgments}

We deeply thank the Vigie Nature volunteers for data collection. We also thank Gino

Nearns and Julie Pauwels for an earlier reading of our manuscript and two anonymous referees for their relevant and useful comments.

\section{REFERENCES}

Azam, C., Le Viol, I., Julien, J.-F., Bas, Y., Kerbiriou, C. 2016. Disentangling the relative effect of light pollution, impervious surfaces and intensive agriculture on bat activity with a national-scale monitoring program. Landscape Ecol. 31, 2471-2483. http//dx.doi.org/10.1007/s10980-016-0417-3

Barataud, M. 2015. Acoustic Ecology of European Bats, Species identification, study of their habitat and foraging behavior. Biotope, Mèze; Muséum national d'histoire naturelle, Paris (Inventaires et biodiversité Series), 352 p.

Barlow, K.E., Briggs, P.A., Haysom, K.A., Hutson, A.M., Lechiara, N.L., Racey, P.A., Walsh, A.L., Langton, S.D., 2015. Citizen science reveals trends in bat populations: The National Bat Monitoring Program in Great Britain. Biol. Conserv. 182, 14-26.

Bas, Y., Bas, D., Julien, J.F. 2017. Tadarida: A Toolbox for Animal Detection on Acoustic Recordings. Journal of Open Research Software 5, 6. http//dx.doi.org/10.5334/jors.154

Battersby, J. 2010. Guidelines for surveillance and monitoring of European bats. EUROBATS Publication Series, 51-95.

Bell, S., M. Marzano, J. Cent, H. Kobierska, D. Podjed, D. Vandzinskaite, H. Reinert, A. Armaitiene, M. Grodzińska-Jurczak, and R. Muršič. 2008. What counts? Volunteers and their organisations in the recording and monitoring of biodiversity. Biodivers. Conserv. 
Couvet, D., Jiguet, F., Julliard, R., Levrel, H., Teyssedre, A. 2008. Enhancing citizen contributions to biodiversity science and public policy. Interdiscipl. Sci. Rev. 33, 95-103.

Boughey, K.L., Lake, I.R., Haysom, K.A., Dolman, P.M. 2011. Effects of landscape-scale broadleaved woodland configuration and extent on roost location for six bat species across the UK. Biol. Conserv.144(9), 2300-2310

Ciechanowski, M., Zajac, T., Bilas, A., Dunajski, R., 2007. Spatiotemporal variation in activity of bat species differing in hunting tactics: effects of weather moonlight, food abundance, and structural clutter. Revue Canadienne de Zoologie 85, 1249-1263.

Claudet, J., Osenberg, C. W., Benedetti-Cecchi, L., Domenici, P., García-Charton, J.-A., Pérez-Ruzafa, Á., Badalamenti, F., Bayle-Sempere, J., Brito, A., Bulleri, F., Culioli, J.M., Dimech, M., Falcón, J. M., Guala, I., Milazzo, M., Sánchez-Meca, J., Somerfield, P. J., Stobart, B., Vandeperre, F., Valle, C., Planes, S. 2008. Marine reserves: size and age do matter. Ecol. Lett. 11, 481-489. http//dx.doi.org/10.1111/j.1461-0248.2008.01166.x

Conrad, K.F., Warren, M.S., Fox R., Parsons, M.S., Woiwod, I.P., 2006. Rapid declines of common, widespread British moths provide evidence of an insect biodiversity crisis, Biol. Conserv. 132(3), 279-291, doi.org/10.1016/j.biocon.2006.04.020.

Crawley, M.J., 2009. The R book. John Wiley \& Sonc, Chicago, USA.

Devictor, V., Godet, L., Julliard, R., Couvet, D., Jiguet, F. 2007. Can common species benefit from protected areas? Biol. Conserv. 139, 29-36.

Denzinger A, Schnitzler H-U. Bat guilds, a concept to classify the highly diverse foraging and echolocation behaviors of microchiropteran bats. Frontiers in Physiology. 4,164. doi:10.3389/fphys.2013.00164.

Donald, P.F., Green, R. E., Heath, M. F. 2001. Agricultural intensification and the collapse of Europe's farmland bird populations. P. Roy. Soc. Lond. B. Bio. 268 25-29. http//dx.doi.org/10.1098/rspb.2000.1325. 
Donald, P.F., Sanderson, F.J., Burfield, I.J., Bierman, S.M., Gregory, R.D., Waliczky, Z. 2007. International conservation policy delivers benefits for birds in Europe. Science $317,810-813$.

Dormann, C.F., McPherson, J.M., Araújo, M.B., Bivand, R., Bolliger, J., Carl, G., Davies, R.D., Hirzel, A., Jetz, W., Daniel Kissling, W., Kühn, I., Ohlemüller, R., Peres-Neto, P.R., Reineking, B., Schröder, B., Schurr, F.M., Wilson, R. 2007. Methods to account for spatial autocorrelation in the analysis of species distributional data: a review. Ecography 30, 609-628.

Donald, P.F., Sanderson, F.J., Burfield, I.J., Bierman, S.M., Gregory, R.D., Waliczky, Z. 2007. International Conservation Policy Delivers Benefits for Birds in Europe. Science. 317(5839), 810-813.

European Commission, Environment, Nature \& Biodiversity http://ec.europa.eu/environment/nature/index_en.htm

European Commission 2000. Managing Natura 2000 sites. The provisions of Article 6 of the ‘Habitats’ Directive 92/43/EEC. European Communities, Luxembourg.

Evans, D. 2012. Building the European Union's Natura 2000 network. Nature Conservation 1, 11. http//dx.doi.org/10.3897/natureconservation.1.1808

Fox, J., Monette, G. 1992. Generalized collinearity diagnostics. Journal of the American Statistics Association 87, 178-183.

Frey-Ehrenbold, A., Bontadina, F., Arlettaz, R., Obrist, M.K. 2013. Landscape connectivity, habitat structure and activity of bat guilds in farmland-dominated matrices. J. Appl. Ecol. 50: 252-261.

Gargominy, O., Tercerie, S., Régnier, C., Ramage, T., Schoelinck, C., Dupont, P., Vandel, E., Daszkiewicz, P., Poncet, L. 2016. TAXREF v10.0, référentiel taxonomique pour la France : méthodologie, mise en oeuvre et diffusion. Muséum national d'Histoire naturelle, Paris. Rapport SPN 2016 - 101. 144 pp.

Gaston, K.J. 2011. Common Ecology. BioScience 61, 354-362. http//dx.doi.org/10.1525/bio.2011.61.5.4 
Gaston, K.J. 2011. Common Ecology. BioScience 61, 354-362. doi:10.1525/bio.2011.61.5.4

572 Gaston, K.J., Jackson, S.E., Nagy, A., Cantu-Salazar, L., Johnson, M. 2008. Protected areas in Europe - Principle and practice. Ann. NY Acad. Sci. 1134, 97-119.

574

Genet, K.S., Sargent, L.G. 2003. Evaluation of Methods and Data Quality from a VolunteerBased Amphibian Call Survey. Wildlife Soc. B. 31, 703-714.

Grindal, S.D., Brigham, R.M., 1999. Impact of forest harvesting on habitat use by foraging insectivorous bats at different spatial scales. Ecoscience 6, 24e34.

Jackson, S.F., Evans, K.L., Gaston, K.J. 2009. Statutory protected areas and avian species richness in Britain. Biodiv. Conserv. 18, 2143-2151.

Jiguet, F., Devictor, V., Julliard, R., Couvet, D. 2011. French citizens monitoring ordinary birds provide tools for conservation and ecological sciences. Acta Oecologica in press

Julliard, R., Jiguet, F., Couvet, D., 2004. Common birds facing global changes: what makes a species at risk? Global Change Biol. 10, 148-154.

Kallimanis, A.S., Touloumis, K., Tzanopoulos, J., Mazaris A.D., Apostolopoulou, E., Stefanidou, S., Scott, A.V., Potts, S.G., Pantis, J.D. 2015. Vegetation coverage change in the EU: patterns inside and outside Natura 2000 protected areas. Biodiv. Conserv.24, 579-591.

Karp, D.S., Rominger, A.J., Zook, J., Ranganathan, J., Ehrlich, P.R. and Daily, G.C. 2012. Intensive agriculture erodes $\beta$-diversity at large scales. Ecol. Lett. 15, 963-970. doi:10.1111/j.1461-0248.2012.01815.x

Kerbiriou, C., Bas, Y. Dufrêne, L. Robert, A. \& Julien J.F. 2010. Long term trends monitoring of bats, from biodiversity indicator production to species specialization assessment. Society for Conservation Biology - 24th Annual Meeting, 3 - 7 July, 2010, Edmonton, Alberta, Canada. 
Kosior, A., Celary, W., Olejniczak, P., Fijal, J., Król, W., Solarz, W., Plonka, P. 2007. The decline of the bumble bees and cuckoo bees (Hymenoptera: Apidae: Bombini) of Western and Central Europe. Oryx 41, 79-88. http//dx.doi.org/10.1017/S0030605307001597.

Kukkala, A.S., Santangeli, A., Butchart, S.H.M., Maiorano, L., Ramirez, I., Burfield, I.J., Moilanen, A. 2016. Coverage of vertebrate species distributions by Important Bird and Biodiversity Areas and Special Protection Areas in the European Union. Biol. Conserv. 202, 1-9. http//dx.doi.org/:10.1016/j.biocon.2016.08.010

Kukkala, A.S., Arponen, A., Maiorano, L., Moilanen, A., Thuiller, W., Toivonen, T., Zupan, L., Brotons, L., Cabeza, M. 2016. Matches and mismatches between national and EU wide priorities: examining the Natura 2000 network in vertebrate species conservation. Biol. Conserv. 198, 193-201.

Kurta, A., Teramino, J.A. 1992. Bat Community Structure in an Urban Park. Ecography, 15, 259-261.

Lacoeuilhe, A., Machon, N., Julien, J.F., Kerbiriou, C. 2016. Effects of hedgerows on bats and bush crickets at different spatial scales. Acta Oecol. 71, 61-72.

Le Viol, I., Jiguet, F., Brotons, L., Herrando, S., Lindström, A., Pearce-Higgins, J.W., Reif, J., Van Turnhout, C., Devictor, V. 2012. More and more generalists: two decades of changes in the European avifauna. Biol. Lett. 8, 780-782. http//dx.doi.org/10.1098/rsbl.2012.0496

Lisón, F., Palazón, J.A. Calvo, J.F. 2013. Effectiveness of the Natura 2000 Network for the conservation of cave-dwelling bats in a Mediterranean region. Animal Conservation 16:528-537. http//dx.doi.org/10.1111/acv.12025

Lisón, F., Sánchez-Fernández, D., Calvo, J.F. 2015. Are species listed in the Annex II of the Habitats Directive better represented in Natura 2000 network than the remaining species? A test using Spanish bats. Biodiv. Conserv. 24(10), 2459-2473. http//dx.doi.org/10.1007/s10531-015-0937-1 
Lisón, F., Sánchez-Fernández, D. 2017. Low effectiveness of the Natura 2000 network in preventing land-use change in bat hotspots. Biodiv. Conserv. 26, 1989-2006.

Loreau, M., Naeem, S., Inchausti, P., Bengtsson, J., Grime, J.P., Hector, A., Hooper, D.U., Huston, M.A., Raffaelli, D., Schmid, B., Tilman, D., Wardle D.A. 2001. Biodiversity and Ecosystem Functioning: Current Knowledge and Future Challenges. Science 294, (5543), 804-808.

Maresca, B., Poquet, G., Ranvier, M., Temple, P., Benevise, F., Dubois, G., Raoul-Duval, J., Ughetto, A.-L. 2006. Evolution économique et institutionnelle du programme Natura 2000 en France, CREDOC. 193 p

Martínez, I., Carreño, F., Escudero, A., Rubio, A. 2006. Are threatened lichen species wellprotected in Spain? Effectiveness of a protected areas network. Biol. Conserv. 133, 500511.

Maxwell, S.L., Fuller, R.A., Brooks, T.M., Watson, J.E.M. 2016. Biodiversity: The ravages of guns, nets and bulldozers. Nature 536, 143-145. http//dx.doi.org/10.1038/536143a

McKinney, M.L. 2006. Urbanization as a major cause of biotic homogenization, Biol.

$$
\text { Conserv. 127(3), 247-260. }
$$

Newson, S.E., Evans, H.E., Gillings, S. 2015. A novel citizen science approach for large-scale standardised monitoring of bat activity and distribution, evaluated in eastern England, Biol. Conserv. 191: 38-49.

O'Donnell, C.F.J. 2000. Conservation status and causes of decline of the threatened New Zealand long-tailed bat Chalinolobus tuberculatus (Chiroptera: Vespertilionidae). Mammal Rev. 30, 89-106.

Orlikowska, E.H., Roberge, J.M., Blicharska, M., Mikusiński, G. 2016. Gaps in ecological research on the world's largest internationally coordinated network of protected areas: a review of Natura 2000. Biol. Conserv. 200, 216-227. 
646 Pellissier, V., Touroult, J., Julliard, R., Siblet, J.P., Jiguet, F. 2013. Assessing the Natura 2000 network with a common breeding birds survey. Ani. Conserv. 16, 566-574. http//dx.doi.org/10.1111/acv.12030

649 Rainho, A, Palmeirim, JM 2011 The Importance of Distance to Resources in the Spatial $650 \quad$ Modelling of Bat Foraging Habitat. PLoS ONE 6(4): e19227

651 Roberts, C.M., Bohnsack, J.A., Gell, F., Hawkins, J.P., Goodridge, R. 2001. Effects of Marine 652 Reserves on Adjacent Fisheries. Science 294(5548), 1920-1923 http//dx.doi.org/10.1126/science.294.5548.1920

654 Rodrigues, A.S.L., Andelman, S.J., Bakarr M.I., Boitani L., Brooks T.M., Cowling R.M., 655 Fishpool L.D.C., Fonseca G.A.B., Gaston K.J., Hoffmann M., Long J.S., Marquet 656

Russo, D., Jones, G. 2003. Use of foraging habitats by bats in a Mediterranean area determined by acoustic surveys: conservation implications. Ecography 26: 197-209 
671

672

673

674

675

676

677

678

679

680

681

682

683

684

685

686

687

688

689

690

691

692

693

694 92 695 of a Broad-Band Acoustic Method. J. Appl. Ecol. 34, 716-730.

Salvarina, I. 2016. Bats and aquatic habitats: a review of habitat use and anthropogenic impacts. Mammal Review 46, 131-143.

Sánchez-Fernández, D., Abellán, P., Picazo, F., Millán, A., Ribera, I., Lobo, J.M. 2013. Do protected areas represent species' optimal climatic conditions. A test using Iberian water beetles. Diversity and Distribution 19, 1407-1417.

Schielzeth, H. 2010. Simple means to improve the interpretability of regression coefficients. Methods in Ecology and Evolution 1:103-113

Schmeller, D.S., Henry, P.-Y.., Julliard, R., Gruber, B., Clobert, J., Dziock, F., Lengyel, S., Nowicki, P., Déri, E., Budrys, E., Kull, T., Tali, K., Bauch, B., Settele, J., Van Swaay, C., Kobler, A., Babij, V., Papastergiadou, E., Henle, K. 2009. Advantages of VolunteerBased Biodiversity Monitoring in Europe. Conserv.Biol. 23, 307-316.

Smith, M.D., Knapp, A.K. 2003. Dominant species maintain ecosystem function with nonrandom species loss. Ecol Lett 6, 509-517.

Solan, M., Cardinale, B.J., Downing, A.L., Engelhardt, K.A.M., Ruesink, J.L., Srivastava, D.S. 2004. Extinction and Ecosystem Function in the Marine Benthos. Science 12, 1177 1180.

Stebbings, R.E, 1988 Conservation of European bats, Christopher Helm, London

Trochet, A., Schmeller, D.S. 2013. Effectiveness of the Natura 2000 network to cover threatened species. Nature Conservation 4: 35-53. http//dx.doi.org/10.3897/natureconservation.4.3626

Van Dyck, H., Van Strien, A.J., Maes, D., Van Swaay, C.A.M. 2009. Declines in Common, Widespread Butterflies in a Landscape under Intense Human Use. Conserv. Biol. 23: 957-965. http//dx.doi.org/10.1111/j.1523-1739.2009.01175.x

Vaughan, N., Jones, G., Harris, S. 1997 Habitat Use by Bats (Chiroptera) Assessed by Means 
696 Verboom, B., Huitema, H., 1997. The importance of linear landscape elements for the

697 pipistrelle Pipistrellus pipistrellus and the serotine bat Eptesicus serotinus. Landscape.

$698 \quad$ Ecol. 12, 117-125.

699 Verboom, B. Spoelstra, K. 1999. Effects of food abundance and wind on the use of tree lines

700 by an insectivorous bat, Pipistrellus pipistrellus. Revue Canadienne de Zoologie 77(9):

701 1393-1401, https://doi.org/10.1139/z99-116

702 Vigie Nature : http://vigienature.mnhn.fr/ (accessed 17.06.13).

703 Voigt, C.C., Kingston, T. 2016. Bats in the Anthropocene: conservation of bats in a changing 704 world. SpringerOpen, New York.Walsh, A.L., Harris, S. 1996. Foraging Habitat 705 Preferences of Vespertilionid Bats in Britain J. Appl. Ecol. 33(3), 508-518

706 Watson, J.E. M., Dudley, N., Segan, D.B. Hockings, M. 2014. The performance and potential 707 of protected areas. Nature 515, 67-73. http//dx.doi.org/10.1038/nature13947

708 Wickramasinghe, L.P., Harris, S., Jones, G., Vaughan Jennings, N. 2004. Abundance and 709 Species Richness of Nocturnal Insects on Organic and Conventional Farms: Effects of 710 Agricultural Intensification on Bat Foraging. Conserv. Biol. 18, 1283-1292.

711 Zehetmair, T., Müllerb, J., Runkel, V., Stahlschmidt, P., Winter, S., Zharov, A., Grupp, A., 712 2015. Poor effectiveness of Natura 2000 beech forests in protecting forest-dwelling bats. 713 Journal for Nature Conservation 23, 53-60.

714 Zuur, A.F., Ieno, E.N., Walker, N., Saveliev, A.A., Smith, G.M., 2009. Mixed Effects Models 715 and Extensions in Ecology with R. Statistics for Biology and Health, Springer, New $716 \quad$ York, USA. 574p. 
718 Table 1. Partial regression coefficient of the raw Natura 2000 effect for the 3 community

719 metrics and 6 taxa.

720

\begin{tabular}{|c|c|c|c|}
\hline Bat activity metric & $\begin{array}{l}\text { Natura } 2000 \text { effect } \\
\text { Estimate }\end{array}$ & $\mathrm{P}$-value & Factor of variation \\
\hline $\begin{array}{l}\text { Relative } \\
\text { abundance }\end{array}$ & $\beta=0.2195 \pm 0.035$ & $P<0.001$ & $\mathrm{x} 1.24$ number of bat passes $/ 2 \mathrm{~km}$ transect \\
\hline Richness & $\beta=0.130 \pm 0.052$ & $P=0.010$ & $\mathrm{x} 1.14$ number of species $/ 2 \mathrm{~km}$ transect \\
\hline CSI & $\beta=0.061 \pm 0.020$ & $P=0.002$ & $\begin{array}{l}\text { x } 1.09 \text { the degree of community } \\
\text { specialization }\end{array}$ \\
\hline P. pipistrellus & $\beta=0.186 \pm 0.041$ & $P<0.001$ & $\mathrm{x} 1.14$ number of passes $/ 2 \mathrm{~km}$ transect \\
\hline P. kuhlii & $\beta=0.113 \pm 0.128$ & $P=0.378$ & \\
\hline E. serotinus & $\beta=0.721 \pm 0.090$ & $P<0.001$ & x 2.05 number of passes $/ 2 \mathrm{~km}$ transect \\
\hline N. noctula & $\beta=-0.346 \pm 0.387$ & $P=0.371$ & \\
\hline N. leisleri & $\beta=0.272 \pm 0.254$ & $P=0.280$ & \\
\hline Myotis spp. & $\beta=1.372 \pm 0.209$ & $P<0.001$ & x 3.68 occurrence of contact $/ 2 \mathrm{~km}$ transect \\
\hline
\end{tabular}


Table 2. Standardized partial regression coefficients from GLMMs model for the 8 landscape effects included in the analysis (i.e. the proportion of the Natura 2000 (Natura 2000), intensive agriculture (Inten. Agri.), heterogeneous agriculture (Heter. agri.), forests (Forests), open habitat (Open habitat) the total length of primary roads (Roads) and streams (Streams) and the average luminance (ALAN)), for the 3 community metrics and 6 taxa and at 4 landscape scales considered. $\mathrm{P}$-value level of significance associated are '***' $\mathrm{P}<0.001 ;{ }^{\prime * *}{ }^{\prime} \mathrm{P}<0.01 ;{ }^{\prime *}{ }^{\prime} \mathrm{P}<0.05$; $\because P<0.1$

\begin{tabular}{|c|c|c|c|c|c|c|c|c|c|}
\hline & Scale & $\begin{array}{c}\text { Natura } \\
2000\end{array}$ & Inten. agri. & $A L A N$ & Heter. agri. & Forests & Open Habitat & Roads & Streams \\
\hline \multicolumn{10}{|c|}{ Community metrics } \\
\hline \multirow{4}{*}{$\begin{array}{l}\text { Relative } \\
\text { abundance }\end{array}$} & 200 & $0.057 * * *$ & $-0.257 * * *$ & $-0.079 * * *$ & $-0.081 * * *$ & -0.008 & $-0.110 * * *$ & $0.0317 * * *$ & $0.016^{*}$ \\
\hline & 500 & $0.022 *$ & $-0.200^{* * *}$ & -0.013 & $-0.029 *$ & $0.051^{*}$ & $-0.047 * *$ & $0.029 * * *$ & $0.028 * * *$ \\
\hline & 700 & $0.028 *$ & $-0.165^{* * *}$ & 0.015 & -0.009 & $0.075 * * *$ & -0.028 & $0.024 * *$ & $0.030 * * *$ \\
\hline & 1000 & 0.030 & $-0.149 * * *$ & 0.023 & -0.010 & $0.081 * * *$ & -0.033 & $0.031 * * *$ & $0.044 * * *$ \\
\hline \multirow{4}{*}{ Richness } & 200 & 0.002 & $-0.206 * * *$ & $-0.083 * * *$ & -0.039 & $-0.045^{*}$ & $-0.071 * *$ & 0.010 & 0.020 \\
\hline & 500 & -0.006 & $-0.157 * * *$ & $-0.055^{*}$ & -0.001 & -0.001 & -0.026 & 0.010 & $0.032 *$ \\
\hline & 700 & -0.009 & $-0.204 * * *$ & $-0.080 * * *$ & -0.039 & $-0.048 *$ & $-0.064 * *$ & 0.005 & $0.034 *$ \\
\hline & 1000 & -0.013 & $-0.217 * * *$ & $-0.089 * * *$ & $-0.047 *$ & $-0.061 *$ & $0.076 * *$ & 0.015 & 0.031 \\
\hline \multirow{3}{*}{ CSI } & 200 & $0.016 * * *$ & $0.040 * * *$ & $-0.028 * * *$ & $-0.042 * * *$ & -0.009 & $-0.030 * * *$ & $0.017 *$ & $0.012 *$ \\
\hline & 500 & $0.013 *$ & $-0.025^{*}$ & $-0.019 *$ & $-0.029 * *$ & 0.007 & 0.019 . & $0.011^{*}$ & $0.010^{*}$ \\
\hline & 700 & $0.013 *$ & $-0.049 * * *$ & $-0.031 * * *$ & $-0.0503 * * *$ & -0.016 & $-0.039 * * *$ & $0.015 * * *$ & 0.009 . \\
\hline
\end{tabular}




\begin{tabular}{|c|c|c|c|c|c|c|c|c|c|}
\hline & 1000 & 0.011 . & $-0.059 * * *$ & $-0.036 * * *$ & $-0.053 * * *$ & $-0.022 *$ & $-0.047 * * *$ & $0.017 * * *$ & 0.008 \\
\hline \multicolumn{10}{|l|}{ Taxa } \\
\hline \multirow{4}{*}{ P. pipistrellus } & 200 & $0.038 * *$ & $-0.219 * * *$ & $-0.087 * * *$ & $-0.073 * * *$ & 0.028 & $-0.109 * * *$ & -0.007 & $0.027^{*}$ \\
\hline & 500 & 0.014 & $-0.175^{* * *}$ & $-0.046^{* *}$ & -0.021 & $0.068 * * *$ & $-0.043 *$ & $-0.042 * * *$ & $0.034 * *$ \\
\hline & 700 & 0.026 & $-0.152 * * *$ & -0.027 & -0.004 & $0.078 * * *$ & -0.028 & 0.004 & $0.031 * *$ \\
\hline & 1000 & $0.043 * *$ & $-0.174 * * *$ & -0.027 & -0.021 & $0.050 *$ & $-0.072 * *$ & 0.009 & $0.048 * * *$ \\
\hline \multirow{4}{*}{ P. kuhlii } & 200 & 0.069 & $-0.328 * * *$ & $-0.169 * * *$ & -0.029 & $-0.150 * * *$ & -0.037 & $0.078 * * *$ & -0.036 \\
\hline & 500 & 0.009 & $-0.255^{* * *}$ & -0.120 & 0.062 & -0.014 & 0.078 & $0.072 * * *$ & -0.016 \\
\hline & 700 & -0.027 & $-0.300 * * *$ & $-0.148^{*}$ & 0.019 & -0.022 & 0.048 & $0.052 * * *$ & 0.007 \\
\hline & 1000 & -0.061 & $-0.370^{* * *}$ & $-0.204 * *$ & -0.006 & -0.030 & 0.021 & $0.045^{*}$ & 0.037 \\
\hline \multirow{4}{*}{ E. serotinus } & 200 & $0.081 * *$ & $-0.706 * * *$ & $-0.353 * * *$ & $-0.346^{* * *}$ & $-0.062 * * *$ & $-0.346 * * *$ & $0.089 * * *$ & $-0.121 * * *$ \\
\hline & 500 & 0.036 & $-0.436 * * *$ & $-0.140 *$ & $-0.190 * * *$ & $0.207 * * *$ & $-0.182 * * *$ & $0.116 *$ & $-0.061 *$ \\
\hline & 700 & 0.026 & $-0.703 * * *$ & $-0.411 * * *$ & $-0.357 * * *$ & 0.007 & $-0.345 * * *$ & $0.077 * * *$ & $-0.059 *$ \\
\hline & 1000 & 0.029 & $-0.722 * * *$ & $-0.297 * * *$ & $-0.397 * * *$ & 0.013 & $-0.441 * * *$ & $0.099 * * *$ & -0.023 \\
\hline \multirow{4}{*}{ N. noctula } & 200 & -0.001 & 0.220 & 0.121 & $-0.486 * * *$ & -0.235 & $-0.676 * * *$ & 0.025 & 0.153 \\
\hline & 500 & -0.001 & -0.242 & 0.043 & $-0.556^{* * *}$ & -0.319 & $-0.807 * * *$ & 0.022 & $0.204^{*}$ \\
\hline & 700 & -0.038 & -0.197 & 0.0001 & $-0.678 * * *$ & -0.204 & $-0.812 * * *$ & 0.175 & $0.212^{*}$ \\
\hline & 1000 & -0.028 & -0.312 & -0.060 & $-0.830 * * *$ & -0.297 & $-0.996^{* * *}$ & $0.203^{*}$ & 0.167 \\
\hline \multirow{3}{*}{ N. leisleri } & 200 & 0.121 & $-0.600 * * *$ & -0.161 & $-0.463^{* * *}$ & $-0.286^{* *}$ & $-0.408 * * *$ & 0.065 & $0.198 * *$ \\
\hline & 500 & 0.133 & $-0.417 * *$ & -0.027 & $-0.390 * * *$ & 0.098 & $-0.329 *$ & 0.004 & $0.188 * *$ \\
\hline & 700 & 0.117 & $-0.571 * * *$ & -0.137 & $-0.585^{* * *}$ & $-0.277^{*}$ & $-0.475 * * *$ & $0.067 * * *$ & $0.190 * *$ \\
\hline
\end{tabular}




\begin{tabular}{llllllllll} 
& 1000 & 0.093 & $-0.598^{* * *}$ & -0.153 & $-0.638^{* * *}$ & $-0.320 * *$ & $-0.551 * * *$ & 0.106. & $0.207 * *$ \\
\hline & 200 & $0.234 * * *$ & $-0.505^{* * *}$ & $-0.208^{*}$ & -0.112 & -0.070 & -0.150. & 0.084. & 0.092. \\
Myotis ssp. & 500 & $0.214^{* *}$ & $-0.526^{* * *}$ & -0.109 & -0.074 & -0.068 & -0.078 & -0.097 & $0.130^{*}$ \\
& 700 & $0.225 * *$ & $-0.527 * * *$ & -0.081 & -0.076 & -0.067 & -0.077 & 0.093. & $0.114 * *$ \\
& 1000 & $0.213 * *$ & $-0.553^{* * *}$ & -0.062 & -0.064 & -0.056 & -0.049 & 0.106. & 0.056 \\
\hline
\end{tabular}


Fig.1 Standardized partial regression coefficients and associated standard errors from GLMMs model for the proportion of the Natura 2000 (Natura 2000), intensive agriculture (Inten. Agri.), forests (Forests), streams (Streams) and average luminance (ALAN) for the total relative abundance (a) and Community Specialization Index (b). The gray gradients correspond to the different buffer sizes. P-value level of significance associated are ‘***’ $\mathrm{P}<0.001 ;{ }^{\prime * *}$ ' $\mathrm{P}<0.01 ;{ }^{\prime *}$ ’ $\mathrm{P}<0.05 ;$ ' ' $\mathrm{P}<0.1$.

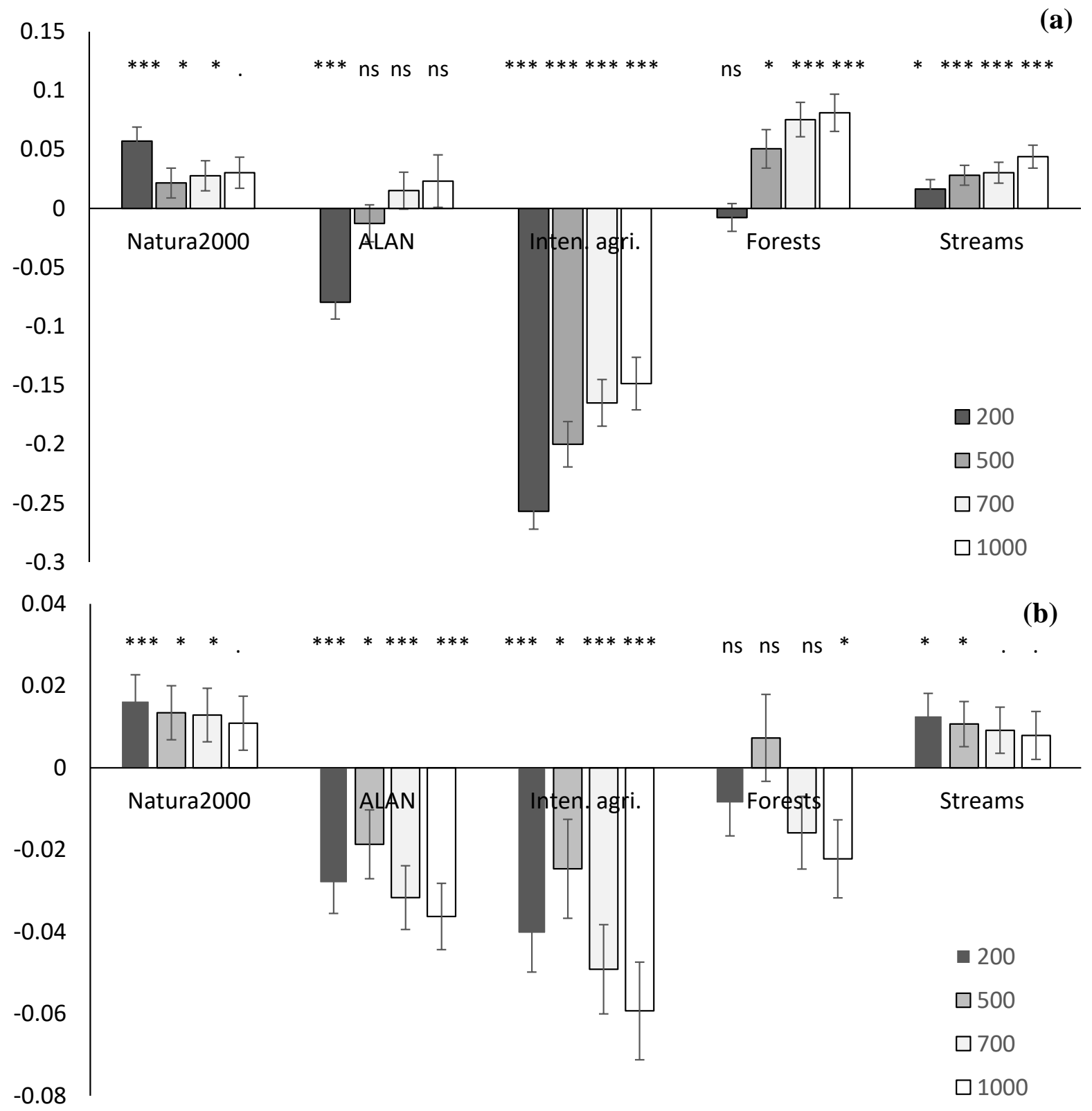




\section{Supplementary Material 1: Detailed information on the French Bat Monitoring Program (FBMP)}

Table S1-1: Characteristics of the protocol and sampling design the two bat surveys

\begin{tabular}{|c|c|}
\hline Aim of the program & $\begin{array}{l}\text { Monitoring the temporal trends of bat populations at a national } \\
\text { scale }\end{array}$ \\
\hline \multicolumn{2}{|c|}{ Car transect survey sampling protocol } \\
\hline Scope & 10 km around surveyors' home. \\
\hline Circuit length & $30 \mathrm{~km}$ \\
\hline Number of transect per circuit & 10 \\
\hline Transect length & $2 \mathrm{~km}$ separated of at least $1 \mathrm{~km}$ \\
\hline Period of sampling & $\begin{array}{l}\text { from the } 15^{\text {th }} \text { of June to the } 31^{\text {th }} \text { of July and } 15 \text { August to } 31 \\
\text { September }\end{array}$ \\
\hline Weather conditions & no rain, low wind speed $(<7 \mathrm{~m} / \mathrm{s})$, temperature $>12^{\circ} \mathrm{C}$ \\
\hline Survey start & as possible 30 minutes after sunset \\
\hline \multicolumn{2}{|c|}{ Count point survey sampling protocol } \\
\hline Scope & $\begin{array}{l}\text { square of } 2 \mathrm{~km} \text {-side randomly chosen (by the Museum) in a radius of } \\
10 \mathrm{~km} \text { from the observer's home, (i.e. on average one square randomly } \\
\text { chosen between } 80 \text { possible squares). }\end{array}$ \\
\hline Circuit length & square of $2 \mathrm{~km}$-side \\
\hline Number of point per circuit & 10 \\
\hline Recording duration & 6 minutes \\
\hline Period of sampling & from the 15 June to 31 July and 15 August to 31 September \\
\hline Weather conditions & no rain, low wind speed $(<7 \mathrm{~m} / \mathrm{s})$, temperature $>12^{\circ} \mathrm{C}$ \\
\hline Survey start & as possible 30 minutes after sunset \\
\hline \multicolumn{2}{|l|}{ Bat recording characteristics } \\
\hline Acoustic detectors & Tranquility Transect Bat detector\&D240x \\
\hline Intercalibration of detectors & At the MNHN \\
\hline Acoustic settings & Tranquility Transect \\
\hline Suppliers & Courtpan Design Ltd, UK \\
\hline High pass filter & $18 \mathrm{kHz}$ \\
\hline Frequency & 96000 sample/sec \\
\hline Recording device & Zoom H2 digital recorder (Samson technologies, USA) \\
\hline File storage format & WAV \\
\hline \multicolumn{2}{|l|}{ Bat identification } \\
\hline Software & Syrinx 2.6 \\
\hline Procedure & $\begin{array}{l}\text { - Training: 2-day training course+ online self-training courses } \\
\text { - Bat first identification: by volunteers } \\
\text { - Bat identification validation: by MNHN }\end{array}$ \\
\hline \multirow[t]{3}{*}{ Taxon identification level } & Species level except for Myotis sp. Extensive data expertise evaluated \\
\hline & that Pipistrellus kuhlii may potentially include $8 \%$ \\
\hline & $\begin{array}{l}\text { Pipistrellus nathusius, as these two species overlap in their acoustic } \\
\text { signatures. }\end{array}$ \\
\hline Meteorological data & $\begin{array}{l}\text { - Temperature }\left({ }^{\circ} \mathrm{C}\right) \text { and cloud cover ( } \% \text { in four classes: } 0-25 \%, 25- \\
50 \%, 50-75 \%, 75-100 \%) \text { were recorded by volunteers during the } \\
\text { survey. }\end{array}$ \\
\hline & $\begin{array}{l}\text { - Wind speed was also recorded by volunteers using Beaufort scale but } \\
\text { this empirical categorical measure was not used in the analyses. } \\
\text { However we used this field this measure to confirm the } \\
\text { appropriateness of the use of the wind speed measure provide } \\
\text { by the closest meteorological station. }\end{array}$ \\
\hline & $\begin{array}{l}\text { - Wind speed }(\mathrm{km} / \mathrm{h}) \text { and humidity }(\%) \text { was provided by the closest } \\
\text { meteorological station using the public archives the web site } \\
\text { Infoclimat [http://www.infoclimat.fr/] }\end{array}$ \\
\hline Habitat data & $\begin{array}{l}\text { Volunteers were involved in collecting habitat variable on } \\
\text { a detailed and adapted hierarchical system (see hereafter). }\end{array}$ \\
\hline
\end{tabular}


Figure S1-1: Example of one road circuit composed of 10 transects

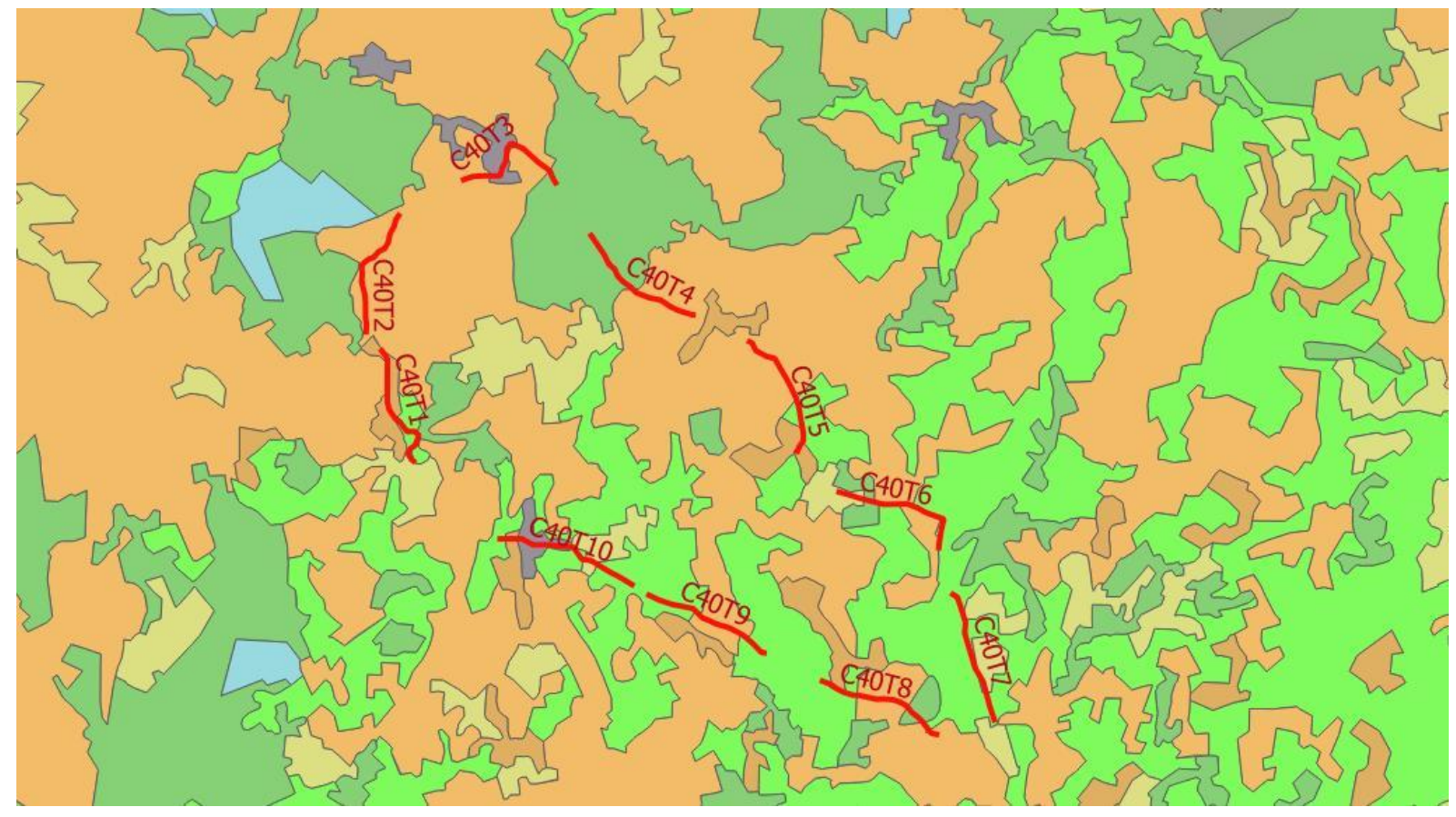

Figure S1-2: Distribution of car transect surveys of the French national bat monitoring program

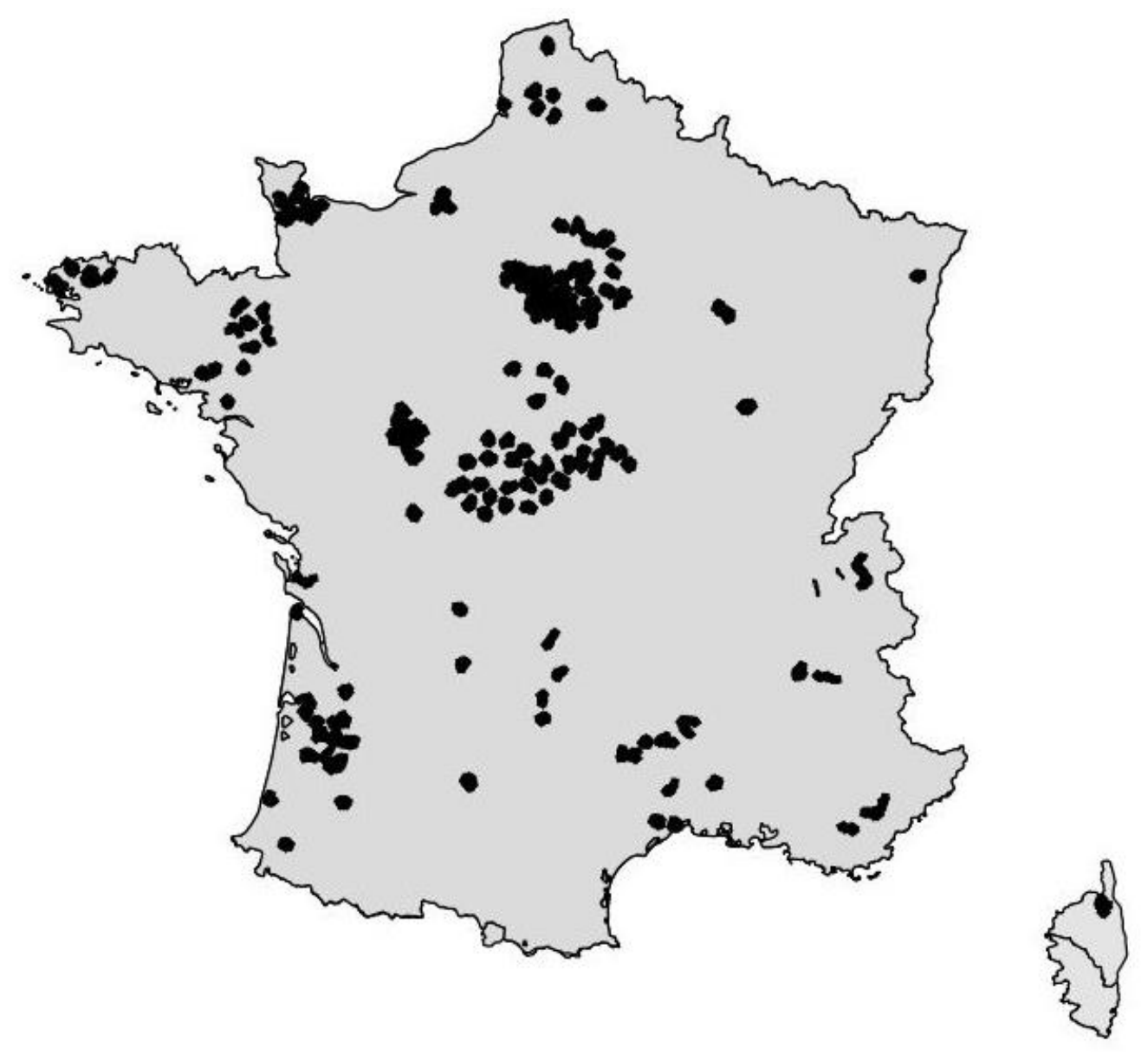




\section{Assessment of potential biases in habitat sampling}

We estimated biases occurring in our monitoring scheme at local and national scales. First, we compared the proportion of different habitats in the $10 \mathrm{~km}$ radius around observers houses in relation to the proportion within 200 meters buffer around each $2 \mathrm{~km}$ transect. Second, we compared to the proportion of different habitats at the French scale to the proportion in 200 meters buffer around each $2 \mathrm{~km}$ transect We used Corine Land Cover data base. With one such sampling design, habitats surveyed are representative of the habitat at the local scale $\left(R^{2}=0.96\right.$; Fig $\left.2-\mathrm{S} 1\right)$ and the national scale $\left(R^{2}=0.95\right.$; Fig $\left.3-\mathrm{S} 1\right)$. The correlation is quite good especially for the commonest habitat and as expected the major difference occurred with rare habitats. The main bias is towards urban areas and particularly discontinuous artificial surfaces which in a $10 \mathrm{~km}$ radius around volunteer's house, represented 5\% of habitat while in the sampled transect the proportion of this habitat reached $10 \%$. The difference is similar when comparing the national habitat proportion to sampled habitat (3\% vs $10 \%)$

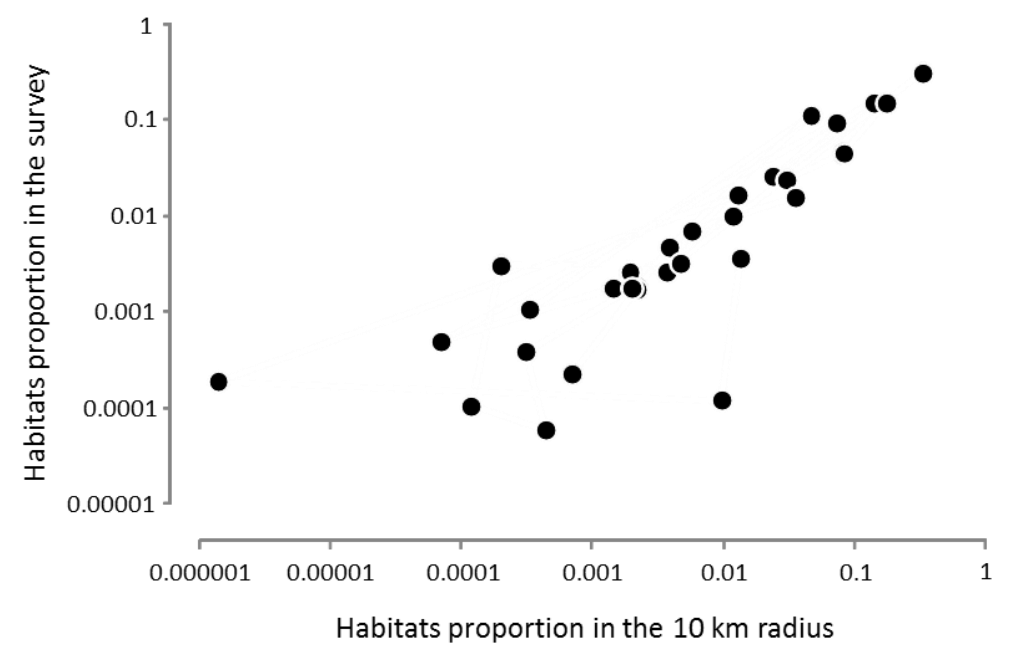

Fig. S1-3: Correlation between habitat proportion at local scale (10 km radius) and proportion sampled in the bat survey. Proportion of Corine Land Cover classes are log transformed.

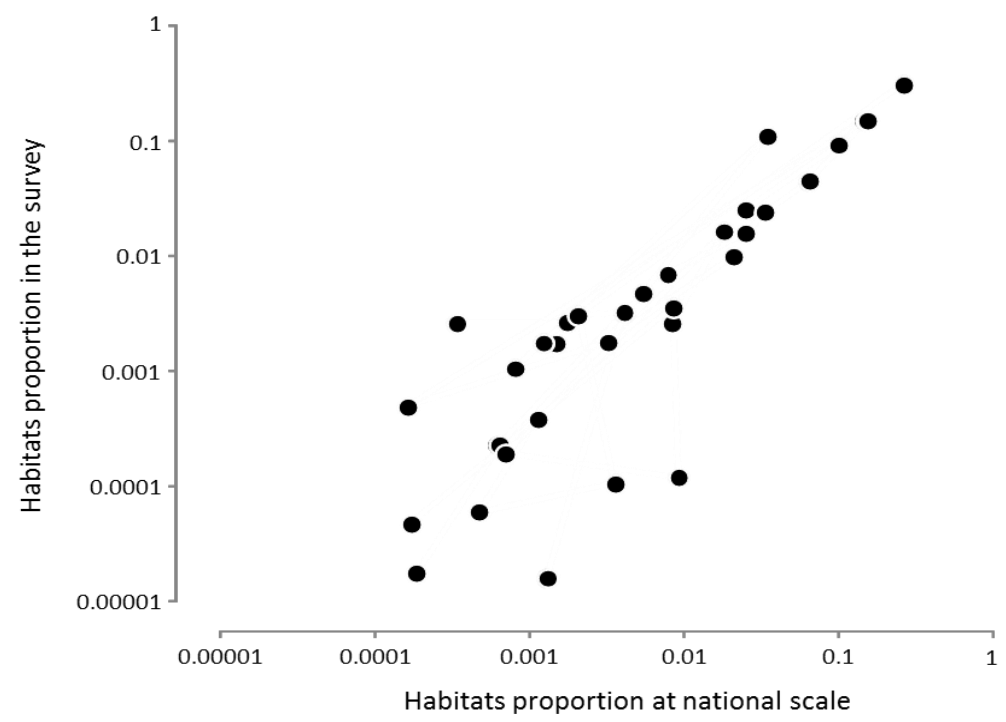

Fig. S1-4: Correlation between habitat proportion at national scale and proportion sampled in the bat survey. Proportion of Corine Land Cover classes are log transformed. 
The coverage of our 160 road circuits representing 1608 different transects was largely representative of French landcover (Table S1-2).

Table S1-2: The land-cover variables surrounding each transect at a range of spatial scales $(200-1000 \mathrm{~m})$, as well as their representativeness in mainland France Landscape. The variables are the proportions of Natura 2000 (Natura 2000), intensive agriculture (Inten. agri.), heterogeneous agriculture (Heter. agri.), deciduous forests (Forests), Open Habitat and mean length per hectare of roads (Roads) and streams (Streams) and the Artificial Light At Night (ALAN), The range represents the minimum and the maximum values encountered for each variable around transects at $1000 \mathrm{~m}$ landscape-scale (similar range were observed for the 3 other landscape scales tested). Proportion of Natura 2000 were similar among landscapescale, however a slight significant positive trend were detected $(P=0.03)$.

\begin{tabular}{|c|c|c|c|c|c|c|}
\hline $\begin{array}{l}\text { Landscape } \\
\text { Variables }\end{array}$ & $\begin{array}{c}\text { Continental } \\
\text { France }\end{array}$ & $\begin{array}{c}\text { Transects } \\
(200 \mathrm{~m})\end{array}$ & $\begin{array}{c}\text { Transects } \\
(500 \mathrm{~m})\end{array}$ & $\begin{array}{c}\text { Transects } \\
(700 \mathrm{~m})\end{array}$ & $\begin{array}{c}\text { Transects } \\
(1000 \mathrm{~m})\end{array}$ & $\begin{array}{c}\text { Range } \\
\text { (min-max) }\end{array}$ \\
\hline & 12.5 & 12.1 & 12.7 & 13.1 & 13.3 & $0-100$ \\
\hline Inten. agri. (\%) & 28.1 & 32.5 & 34.0 & 34.3 & 34.9 & $0-100$ \\
\hline Heter. agri. (\%) & 11.0 & 12.9 & 11.5 & 11.8 & 11.4 & $0-92$ \\
\hline Forests (\%) & 19.9 & 18.6 & 24.7 & 20.7 & 21.2 & $0-100$ \\
\hline Open habitat (\%) & 18.5 & 15.9 & 15.7 & 15.7 & 16.3 & $0-99$ \\
\hline Imper. surf. (\%) & 5.2 & 11.3 & 8.74 & 7.3 & 6.5 & $0-92$ \\
\hline Roads (m) & 1.92 & 12.8 & 6.8 & 5.4 & 4.3 & $0-9391$ \\
\hline Streams $(m)$ & 6.67 & 12.9 & 10.5 & 9.8 & 9.1 & $\begin{array}{c}0- \\
22262\end{array}$ \\
\hline$A L A N$ & 3.2 & 2.2 & 2.2 & 2.1 & 2.1 & $0.1-35$ \\
\hline
\end{tabular}

No obvious correlation (rho $\geq 0$.5; Freckleton, 2002) was detected between landuse variables and Natura2000 (Table S1-3)

\section{Assessment of potential bias of habitat characteristics between sampling within and outside Natura 2000 areas.}

Because foraging activity of bats is not only influenced by the type of natural habitat type but also by small scale habitat characteristics in the agricultural landscape, such as the presence of linear elements like hedges (Limpens et al., 1989; Krusic et al., 1996; Verboom \& Huitema, 1997; Downs \& Racey, 2006), we have attempt to evaluate possible bias between sampling areas surveyed within and outside Natura 2000 areas. In forest habitat, we evaluated potential bias linked with the recording position: recording along forest paths or at forest edge.

\subsection{Methods}

2.1.1. Data

In the French national bat monitoring volunteers were involved in collecting habitat variable on a detailed and adapted basis. Habitat information is recorded on the first reconnaissance visit to the circuit. The appropriate habitat codes are chosen from an established hierarchical system which is very similar to widely use habitat code in bird monitoring schemes (see Crick 1992 for the UK and Barnagaud et al., 2012 for the French monitoring), but adapted to take account of bat foraging specifics and particularly linear element (for more details about the French Bat monitoring see the website [http://vigienature.mnhn.fr/page/releves-d-habitats]). 
Volunteers are invited to record habitat characteristic every $400 \mathrm{~m}$ along $2 \mathrm{~km}$ transects. Currently more than $55 \%$ of circuits have been described by volunteers.

\subsubsection{Statistical analysis}

We assess the presence of potential sampling bias among areas within Natura 2000 designation or without using Generalized Linear Model (GLM) with a quasi-binomial error distribution.

In agricultural habitat, we test the possible difference of linear element within or without Natura 2000 areas according to agricultural habitat classes (Heterogeneous agricultural areas, Arable land, Pastures, Vineyards \& orchard). We detect a slight trend of lower proportion of hedgerow within an Natura 2000 area (Table S1-3), not however that except for the Arable land the differences are quite weak.

Table S1-3: Probability to encounter a hedgerow, in the collected samples, according the fact being within or without a Natura 2000 area.

\begin{tabular}{lccl}
\hline & Effect & P-value & Probability \\
\hline Arable land $(n=454)$ & $\beta=-1.460$ & $\mathrm{P}<0.0001$ & $\begin{array}{l}\text { Within Natura 2000 area: } 0.09 \\
\text { Without Natura 2000 area: } 0.28\end{array}$ \\
\hline $\begin{array}{l}\text { Heterogeneous agricultural areas } \\
(n=811)\end{array}$ & $\beta=-0.850$ & $\mathrm{P}<0.0001$ & $\begin{array}{l}\text { Within Natura 2000 area: } 0.79 \\
\text { Without Natura 2000 area: } 0.90\end{array}$ \\
\hline Pastures $(n=643)$ & & $\mathrm{P}=0.11$ & Within Natura 2000 area: 0.85 \\
& $\beta=-0.377$ & & Without Natura 2000 area: 0.89 \\
\hline Vineyards \& orchard $(n=63)$ & $\beta=-0.000$ & $\mathrm{P}=1$ & $\begin{array}{l}\text { Within Natura 2000 area: } 0.50 \\
\text { Without Natura 2000 area: } 0.50\end{array}$ \\
\hline
\end{tabular}

In forest habitat, we evaluate the existence of potential bias of recording position (in forest path or in forest edge) among areas within Natura 2000 designation or without. This effect was adjusted to forest habitat classes (Broad-leaved forest, Coniferous forest, Mixed forest dominant broad-leaved, Mixed forest dominant coniferous). Except for the Coniferous forest (note the small sample) the differences are quite weak, even if statistically significant (table S1-4).

Table S1-4: Probability to being located in a forest path instead a forest edge, in the collected samples, according the fact being within or without a Natura 2000 area.

\begin{tabular}{|c|c|c|c|}
\hline & Effect & P-value & Probability \\
\hline Broad-leaved forest $(n=989)$ & $\beta=0.465$ & $\mathrm{P}=0.009$ & $\begin{array}{l}\text { Within Natura } 2000 \text { area: } 0.82 \\
\text { Without Natura } 2000 \text { area: } 0.75\end{array}$ \\
\hline $\begin{array}{l}\text { Mixed forest dominant broad- } \\
\text { leaved }(n=572)\end{array}$ & $\beta=-0.603$ & $\mathrm{P}=0.04$ & $\begin{array}{l}\text { Within Natura } 2000 \text { area: } 0.87 \\
\text { Without Natura } 2000 \text { area: } 0.92\end{array}$ \\
\hline Coniferous forest $(n=55)$ & $\beta=-16.99$ & $\mathrm{P}=0.9$ & $\begin{array}{l}\text { Within Natura } 2000 \text { area: } 0.14 \\
\text { Without Natura } 2000 \text { area: } 0.66\end{array}$ \\
\hline $\begin{array}{l}\text { Mixed forest dominant coniferous } \\
(n=263)\end{array}$ & $\beta=-1.331$ & $\mathrm{P}=0.02$ & $\begin{array}{l}\text { Within Natura } 2000 \text { area: } 0.86 \\
\text { Without Natura } 2000 \text { area: } 0.96\end{array}$ \\
\hline
\end{tabular}




\section{Device fastener}
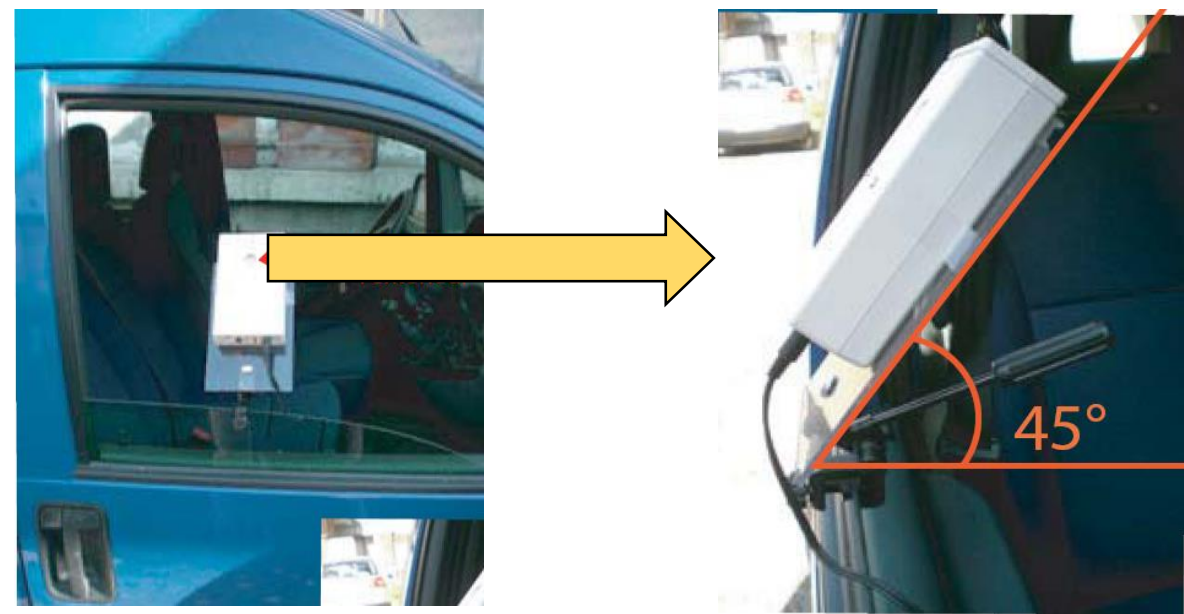

Fig S1-1: arrangement of the detector. The detector was fixed to the passenger-side window at a $45^{\circ}$ angle so that the distance to road edges was similar all along the circuits

\section{Recording characteristic}

Bats calls were detected using a Tranquility Transect Bat detector (Courtpan Design Ltd, UK) and D240x (Pettersson Elektronik) and recorded on a Zoom H2 digital recorder (Samson technologies, USA). Before used all detector are calibrated at the French National Museum History in order to obtain the same level of sensibility. Signal from the condenser microphone of the bat detector was internally amplified and high pass filtered with a $5 \mathrm{kHz}$ corner frequency and fed to the Zoom H2 which recorded it at 96000 sample/s as PCM files. Sound was stored on Secured Card in Waveform Audio File Format more commonly known as WAV format, a format without compression. Tranquility Transect set to record $0.32 \mathrm{~s}$ of sound at x10 time expansion. Each recorded $0.32 \mathrm{~s}$ is followed by $3.2 \mathrm{~s}$ of playback, during which time the detector does not record. For the D240x the most similar storage time is 0.1 seconds of sound instead of 0.32 , thus we performed a posteriori elimination of time expansion sequences that were spaces of less than 3.2 seconds. All ultrasound detectors were previously calibrated by the French National Museum of Natural History in order to have the trigger level.

\section{Bat identification}

Species acoustic identification was done by volunteer surveyors using Syrinx software version 2.6 (Burt 2006), followed by an identification validation by Museum experts. This approach allows identification difficulties to be highlighted, also volunteers become expert through training sessions (each year the museum offers free training for volunteers) and through some kind of self-training thanks to the corrected identification forms we send back.

Table S1-6: Identification error rate of volunteers after one training session

\begin{tabular}{ll}
\hline Pipistrellus pipistrellus & $1.6 \%( \pm 0.5)$ \\
Pipistrellus kuhlii & $7.8 \%( \pm 1.9)$ \\
Nyctalus leisleri & $6.4 \%( \pm 1.5)$ \\
Eptesicus serotinus & $9.7 \%( \pm 2.7)$ \\
\hline
\end{tabular}

Identifications were analyzed call by call and in the case of ambiguous call patterns, we encourage volunteers to use Scan'R (Binary Acoustic Technology, 2010) to isolate each bat vocalization and automate the measurement of relevant parameters (Russ 1999; Barataud 
2012; Gannon et al., 2004; Obrist et al., 2004). The main relevant parameters used were: call duration (msec), time elapsed since between calls (msec), maximum frequency detected (Fmax, KHz), minimum frequency detected (Fmin, KHz), total bandwidth [Fmax - Fmin] $(\mathrm{KHz})$, frequency at strongest sound pressure level $(\mathrm{KHz})$, location of dominant Frequencies (\% of total duration), high end of characteristic (KHz) [Similar to $\mathrm{Fk}$ ], low end of characteristic $(\mathrm{KHz})$ [Similar to $\mathrm{Fc}$ ], global slope of the call ( $\mathrm{KHz}$ per msec), time of the heel or High Fc (percent of duration), upper slope [start to High Fc] (KHz per msec), lower slope [High $\mathrm{Fc}$ to Low $\mathrm{Fc}$ ] (KHz per $\mathrm{msec}$ ), fundamental frequency $(\mathrm{KHz})$, 2nd harmonic frequency $(\mathrm{KHz})$, curvature measurement as a way to characterize the shape of bat calls, curve fit error parameter; a measurement of how much error exists between the curvature model and the actual shape of the call.

Each contact was assigned to the species level, however due to the lack of general consensus for some species about the acoustic criteria and some overlap between acoustic repertoires, it was not possible to assign the exact species with certainty for all calls; thus

- (i) we constructed a group for species from the Myotis genus. Note that some species included in the same group may have different ecology, however, from a foraging behavior perspective, these groups have some convergences. The Myotis group primarily included species considered to be gleaners, which capture the majority of their prey from substrates in cluttered environments (Arlettaz et al., 2001). These species eat mainly diurnal brachyceran Diptera and non-volant arthropod such as weevils, lepidopteran larvae, harvestmen and spiders (Dietz et al., 2007). In addition note that the group Myotis exhibit avoidance behavior to artificial light points such street lamp (Lacoeuilhe et al. 2014; Azam et al., 2015). Among this Myotis ssp. group, the majority of Myotis identified at the species level were Myotis daubentoni.

- (ii) we estimate that among $P$. kuhlii may potentially include some $P$. nathusii, indeed these two species have some overlap between acoustic repertoires. Extensive validations with experts on more than $58 \%$ of the whole data indicate that probably less than $8 \%$ of the $P$. kuhlii identifications are not entirely certain and that it resides a small probability that it can be alternatively be $P$. nathusius. Note that these two species forage mostly on flying prey in open spaces (Dietz et al., 2007) and are "attracted" by artificial light points such street lamp (Lacoeuilhe et al. 2014, Azam et al. 2015).

Table S1-7: composition of the Myotis spp category

\begin{tabular}{lr}
\hline Species & $\%$ \\
\hline Myotis alcathoe & 0.1 \\
Myotis bechsteinii & 0.2 \\
Myotis brantii & 0.6 \\
Myotis capaccini & 0.0 \\
Myotis daubentoni & 34.7 \\
Myotis emarginatus & 0.5 \\
Myotis myotis & 1.8 \\
Myotis mystacinus & 1.9 \\
Myotis nattereri & 1.8 \\
Myotis puniclus & 0.0 \\
Myotis sp & 58.3 \\
\hline
\end{tabular}




\section{Bat activity measure}

We stored the same bat signal with the two possible outputs of the detector: time expansion $\left(t_{\text {exp }}\right)$ and high frequency $\left(t_{h f}\right)$. Time expansion is the format widely used from the beginning of the FBMP and bat activity index (name in this study relative abundance) is built with this format. It is often possible to discern echolocation pulses from more than one individual bat in one sound interval, based for example on differing frequencies of maximum energy $\left(F_{\max }\right)$ and inter-pulse intervals between echolocation calls. Time expansion is used from the Bat Ireland monitoring (Roche et al. 2011) and in numerous countries through the ibats programs. With time expansion and with our setting each recorded $0.32 \mathrm{~s}$ is followed by $3.2 \mathrm{~s}$ of playback, during which time the detector does not record. High frequency outputs, is a continuous sound recording that allow considers the duration of bat call passes. Thus this measure is certainly a best descriptor of bat activity, however identification on this format it is very time consuming and require greater expert knowledge. Volunteers are not requested to identify high frequency format and thus very few identification of the FBMP come from this format. This format was used to assess bat pass duration (Fig S1-2).
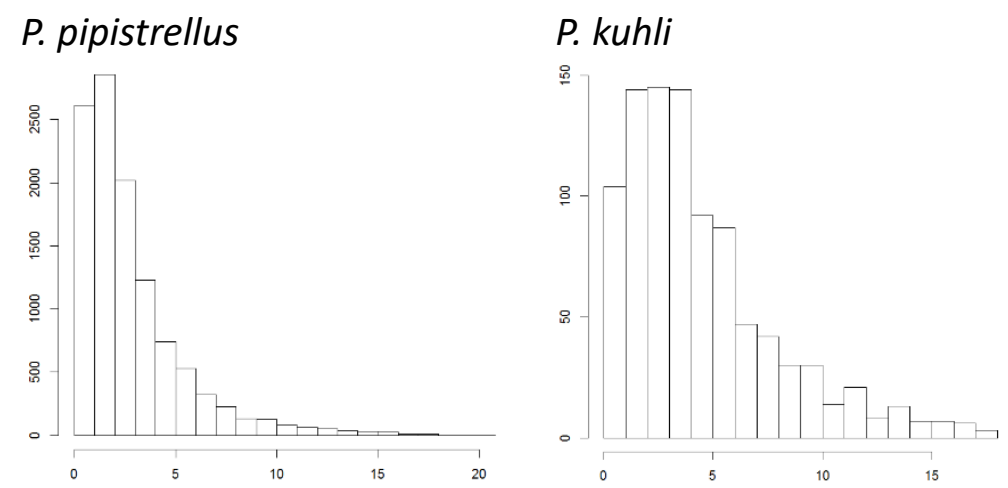

\section{E. serotinus}

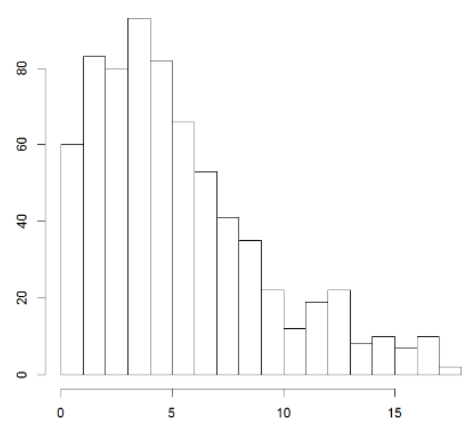

N. Leisleri

N. noctula

Myotis ssp
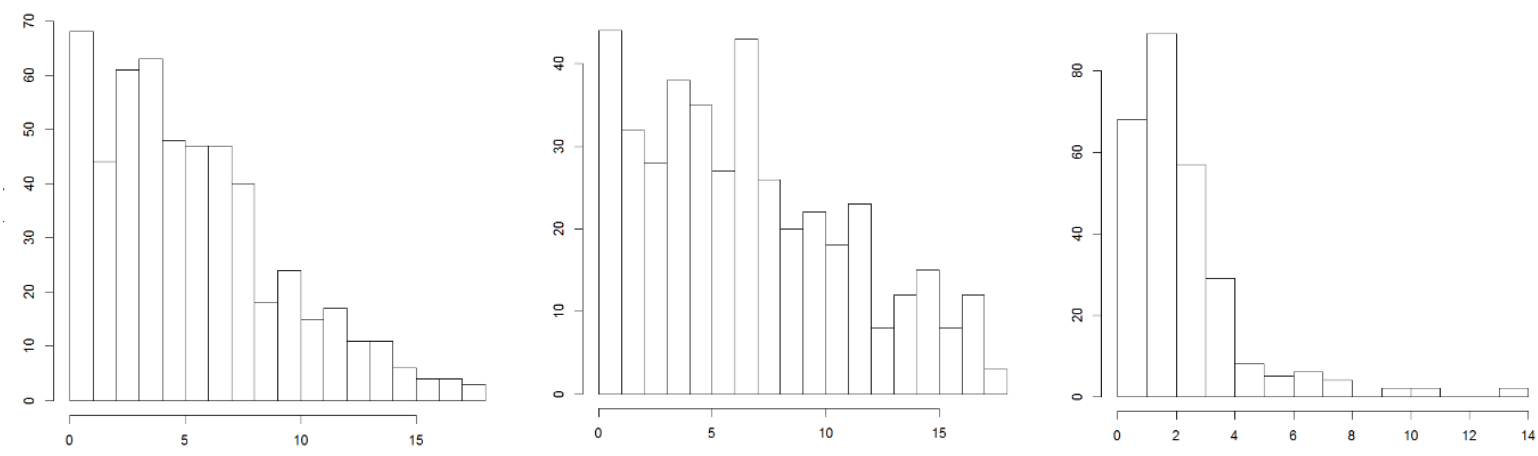

Fig S1-2: Distribution of bat passes duration from the car transect survey (vertical axis are the number of bat pass)

With the bat detector setting, (each recorded $0.32 \mathrm{~s}$ is followed by $3.2 \mathrm{~s}$ ), a detector is able to detect the following contact only $3.52 \mathrm{~s}$ after the previous contact. This following contact could be either the same individual or another individual. However, according that (i) the car rolls at $25 \mathrm{Km} / \mathrm{h}$ at the time of the recordings, $3.52 \mathrm{~s}$ mean that car is 25 meters away (ii) the bat pass duration distribution (see Fig S1-2) and (iii) the distance of detection of bat (see Barataud 2015), we hypothesize that multiple counts of the same individual may be rare and concern mainly Nyctalus spp and E. serotinus. 


\section{Variation of the sampling between years}

Fig S1-3 .Number of available transects surveyed per years

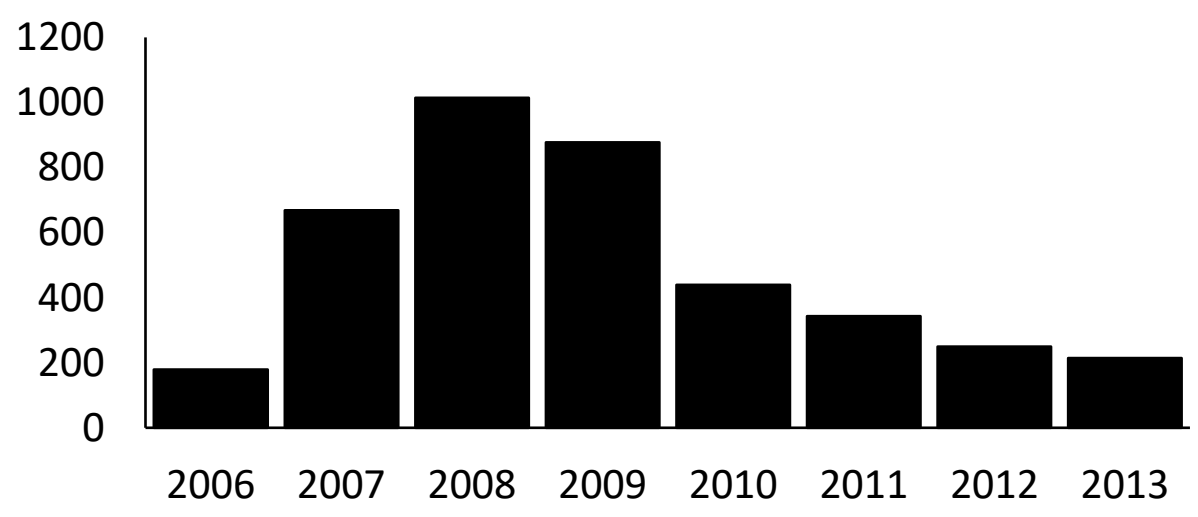

\section{LITTERATURE CITED}

Azam C., Kerbiriou C., Vernet A., Julien J.F., Bas Y., Plichard L., Maratrat J., Le Viol I., 2015. Part-night lighting: an efficient measure to limit the impacts of light pollution on bats? Global Changes Biol. 21, 4333-4341.

Barataud, M., 2012. Ecologie acoustique des chiroptères d'Europe. Identification des espèces, études de leurs habitats et comportements de chasse. Biotope, Mèze ; Muséum national d'histoire naturelle, Paris (collection Inventaires et biodiversité), $344 \mathrm{p}$.

Barnagaud J.-Y., Devictor V., Jiguet F., Barbet-Massin M., Le Viol I., et al. 2012. Relating Habitat and Climatic Niches in Birds. PLoS ONE 7(3), e32819.

Crick, H.Q.P. (1992): A bird-habitat coding system for use in Britain and Ireland incorporating aspects of land-management and human activity. Bird Study 39, 1-12.

Dietz, C., Nill, D., Von Helversen, O., Lina, P.H.C., Hutson, A.M., 2007. Bats of Britain, Europe and Northwest Africa. Franck-Kosmos Verlags, London, UK, pp. 400pp.

Downs, N.C., Racey, P.A. 2006. The use by bats of habitat features in mixed farmland in Scotland. Acta Chiropterologica 8, 169-185

Freckleton, R.P. 2002. On the misuse of residuals in ecology: regression of residuals vs. multiple regression. J. Anim. Ecol. 71, 542-545.

Gannon, W.L., O'Farell M.J., Corben, C., Bedrick, E., 2004. Call character Lexicon and analysis of field recorded bat echolocation calls. Echolocation in bats and dolphinsEdited by J.A. Thomas, CF Moss, and Vater. 2004. University of Chicago Press, Chicago, IL, USA, 604 pp.

Krusic, R.A., Yamasaki, M., Neefus, C.D. and Pekins, P.J. 1996. Bat Habitat Use in White Mountain National Forest. The Journal of Wildlife Management 60, 625-631

Lacoeuilhe A., Machon N., Julien J.F., Le BocqA., Kerbiriou C. 2014. The influence of low intensities of light pollution on bat communities in a semi-natural context. PLOS ONE. published31 Oct 2014

Limpens A.H., Helmer W., Van Winden A., and Mostert, K. 1989. Bats (Chiroptera) and linear landscape elements: a review of our present knowledge of the importance of linear landscape elements to bats. Lutra 32, 1-20 
Obrist, M.K., Boesch, R., Flückiger, P.F. 2004. Variability in echolocation call design of 26 Swiss bat species: consequences, limits and options for automated field identification with a synergetic pattern recognition approach. Mammalia 68 (4), 307-322.

Russ J 1999. The Bats of Britain and Ireland: Echolocation Calls, Sound Analysis and Species Identification. Alana Books, Bishop's Castle. 103 p.

Verboom, B., Huitema H. 1997. The importance of linear landscape elements for the pipistrelle Pipistrellus pipistrellus and the serotine bat Eptesicus serotinus. Landscape Ecol. 12, 117-125 


\section{Supplementary material 2: Detailed information on the calculation of specialization indices}

In the French national bat monitoring volunteers were involved in recording habitat. Habitat information is recorded on the first reconnaissance visit to the circuit. The appropriate habitat codes are chosen from an established hierarchical system allowing describe more than 950 habitat type, which is very similar to widely use habitat code in birds monitoring schemes (see Crick 1992 for the UK and Barnagaud et al., 2012 for the French monitoring), but adapted to take into account bat foraging specificities and particularly linear element (for more details about the French Bat monitoring see the website [http://vigienature.mnhn.fr/page/releves-dhabitats]). Habitat classes are collected in a radius of $100 \mathrm{~m}$ around the sampled point and grouped into 18 classes in order to obtain sufficient number of sample per class (for more methodological information see Julliard et al., 2006; DeVictor et al., 2008; Kerbiriou et al. 2010).

Specialization species index (SSI)

We quantified the species specialization index (SSI), which is the degree of habitat specialization for a species, as the coefficient of variation ( $\mathrm{SD} / \mathrm{mean})$ of its densities across habitats following Julliard et al.'s approach (2006). SSI is thus independent to species habitat preferences. However, it is also possible to assess the species specializations to forest habitats by calculating the average density of a species inventoried in forest habitats divided by the average density in non-forest habitats.

Table S2-1: Habitat Specialization Index, NA indicates that data are insufficient for this species to allow a robust estimate of SSI.

\begin{tabular}{lc}
\hline Bat species & Habitat Specialization Index \\
\hline Barbastella barbastellus & 3.64 \\
Eptesicus serotinus & 1.50 \\
Myotis myotis & NA \\
Myotis daubentonii & 3.48 \\
Myotis mystacinus & 3.86 \\
Myotis nattereri & 2.40 \\
Nyctalus leisleri & 0.95 \\
Nyctalus noctula & 1.58 \\
Pipistrellus kuhlii & 0.75 \\
Pipistrellus nathusii & 3.06 \\
Pipistrellus pipistrellus & 0.54 \\
Pipistrellus pygmaeus & 1.79 \\
Plecotus sp (mainly austriacus) & 1.36 \\
Rhinolophus hipposideros & NA \\
\hline
\end{tabular}

Assessment of bat community specializations indices

The Community Specialization Index (CSI) is calculated as the arithmetic mean of the species specialization index (SSI) of the species detected, weighted by the abundances (Julliard et al., 2006). 
$\mathrm{CSI}_{\mathrm{j}}=\frac{\sum_{\mathrm{i}=1}^{\mathrm{n}} a_{\mathrm{ij}}\left(\mathrm{SSI}_{\mathrm{i}}\right)}{\sum_{\mathrm{i}=1}^{\mathrm{n}} a_{\mathrm{ij}}}$

where $n$ is the total number of species recorded, $a_{i j}$ is the abundance of individuals of species $i$ (with a SSI specialization index) in segment $\mathrm{j}$ (Devictor et al., 2008).

The CSI reflects the relative abundance of more or less specialized species in local assemblages and is therefore expected to decrease following the relative declines of specialists (species with a high SSI). For the analyses, we kept only site with a non-null abundance because a null CSI does not describe a generalist community.

\section{LITTERATURE CITED}

Barnagaud J.-Y., Devictor V., Jiguet F., Barbet-Massin M., Le Viol I., et al. 2012. Relating Habitat and Climatic Niches in Birds. PLoS ONE 7(3), e32819. doi:10.1371/journal.pone.0032819

Crick, H.Q.P. 1992. A bird-habitat coding system for use in Britain and Ireland incorporating aspects of land-management and human activity. Bird Study 39: 1-12

Devictor, V., Julliard, R., Jiguet, F., 2008. Distribution of specialist and generalist species along spatial gradients of habitat disturbance and fragmentation. Oikos 117: 507514.

Julliard, R., Clavel, J., Devictor, V., Jiguet, F., Couvet, D., 2006. Spatial segregation of specialists and generalists in bird communities. Ecol. Lett. 9: 1237-1244.

Kerbiriou, C., Bas, Y., Dufrêne, L., Robert, A., Julien, J.F., 2010. Long term trends monitoring of bats, from biodiversity indicator production to species specialization assessment. Society for Conserv. Biol. - 24th Annual Meeting, 3 - 7 July, 2010, Edmonton, Alberta, Canada. 
Supplementary material 3: Description of the Natura 2000 network in France

The Natura 2000 network is regulated by two directives: following the Bird Directive of the European Union (79/409/EC), 384 Special Protection Areas (thereafter SPA, Fig.S1) were designated in France to protect endangered bird species, from 1986 onwards. The other Natura 2000 areas are Special Areas of Conservation (thereafter SAC, Fig.S2) which are defined following the Habitat Directive of the European Union (92/43/EEC) to protect nonbird animals and plant species and habitats listed in the Annexes I and II of this directive. These areas are identified as Sites of Community Importance (thereafter SCI, Fig.S2) and after approval of the European Union designated as SAC. To date, in France, circa the half of the 1369 SCI were further designated as SAC and thus effectively protected, since 2005 . As a whole (SCI/SAC and SPA combined), the Natura 2000 networks represents $12.5 \%$ of the continental territory of France. After the designation phase occurring in 2000/2005, the Natura 2000 network is now engaged in a growing management process, based on management plans, voluntary measures and impact assessment prior to new human activities.

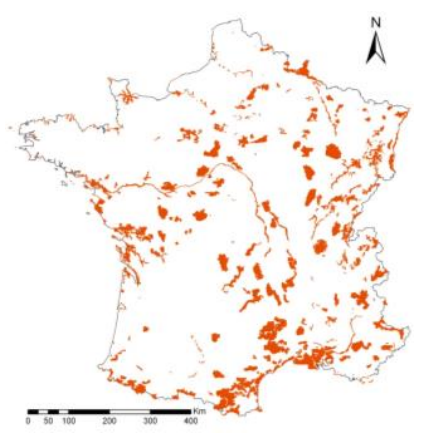

Figure S3-1. Location of the 384 Special Protection Areas (SPA) in France

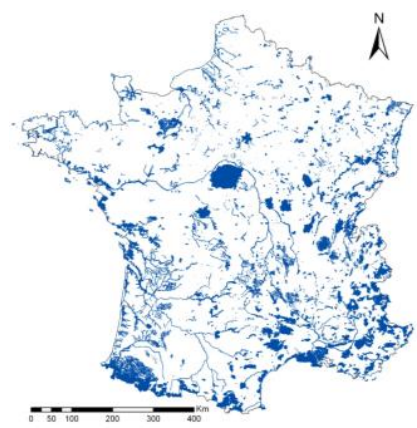

Figure S3-2. Location of the 1369 Sites of Community Interest (SCI) to be designated as Special Areas for Conservation (SACs) by the European Union 


\section{Supplementary material 4: Detailed information on the variable Artificial Light at Night (ALAN)}

We used radiance as a measure of ALAN as it is defined as the radiant flux (i.e., radiant power) reflected or emitted by a given surface. We used the VIIRS nighttime lights (2012) which is a 2-months composite raster of radiance data (in $\mathrm{nW} / \mathrm{cm}-2 \mathrm{sr}$ ) collected by the Suomi NPP-VIIRS Day/ Night Band during 2 time-periods in 2012 (20 nights in total) on cloud-free nights with zero moonlight (Baugh et al. 2013). We then computed the average radiance within each buffer with the tool "Zonal statistics as Table" from the package “'Spatial Analyst”' (Fig. S1, see also Azam et al. 2016).
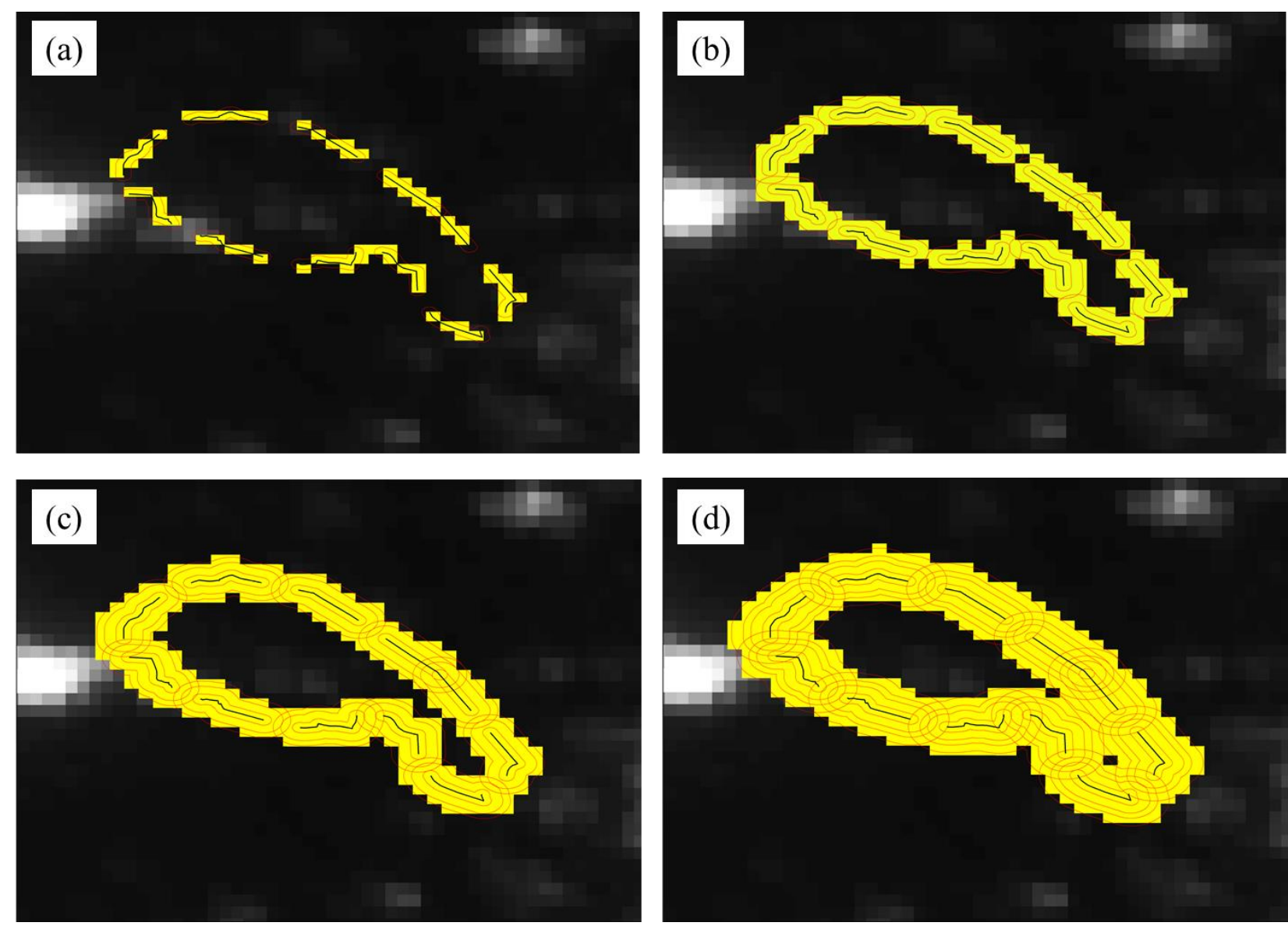

Fig. S1 Demonstration of the procedure done to calculate average radiance within the buffers of (a) $200 \mathrm{~m}$, (b) $500 \mathrm{~m}$, (c) $700 \mathrm{~m}$ and (d) $1000 \mathrm{~m}$ width from the VIIRS Nighttime Light raster used to. The average radiance was computed by the tool "zonal statistics as Table" from the package "Spatial Analyst" of ArcGIS 10.2 which proceed by creating a raster (yellow) from the polygon shapefile input (red) before applying an internal resampling so that input raster resolution match with the value raster resolution.

\section{LITTERATURE CITED}

Azam C., Le Viol I., Julien J.-F., Bas Y., Kerbiriou C. 2016. Disentangling the relative effect of light pollution, impervious surfaces and intensive agriculture on bat activity with a national-scale monitoring program. Landscape Ecol. 31(10), 2471-248.

Baugh K., Hsu F.-C., Elvidge C.D., Zhizhin M 2013. Nighttime lights compositing using the VIIRS day-night band: preliminary results. Proc Asia-Pac Adv Netw 35, 70-86 


\section{Supplementary material 5: Detailed information on statistical analysis}

Table S5-1 Correlation coefficients of the 8 landscape variables included in the analysis (i.e. The variables are the proportions of Natura 2000 (Natura 2000), intensive agriculture (Inten. agri.), heterogeneous agriculture (Heter. agri.), deciduous forests (Forests), Open Habitat and mean length per hectare of roads (Roads) and streams (Streams) and the Artificial Light At Night (ALAN), at the $1000 \mathrm{~m}$ landscape-scale which showed the strongest the correlation coefficients between landscape variables.

\begin{tabular}{llllllll}
\hline & ALAN & Inten. agri & $\begin{array}{l}\text { Heter. } \\
\text { agri.. }\end{array}$ & Forests & $\begin{array}{l}\text { Open } \\
\text { Habitat }\end{array}$ & Roads & Streams \\
\hline Natura 2000 & -0.25 & -0.36 & 0.004 & 0.14 & 0.32 & 0.09 & 0.19 \\
ALAN &. & -0.10 & -0.14 & -0.07 & -0.39 & 0.13 & 0.02 \\
Inten. agri. & $/$ & - & -0.32 & -0.46 & -0.58 & 0.04 & -0.30 \\
Heter. agri. & $/$ & - & $/$ & -0.25 & 0.23 & -0.007 & 0.09 \\
Forest & $/$ & - & $/$ & $/$ & -0.15 & -0.02 & -0.007 \\
Open Habitat & - & - & - & - & - & 0.06 & 0.33 \\
Roads & $/$ & - & $/$ & $/$ & - & $/$ & -0.009 \\
\hline
\end{tabular}

Table S5-2: Selected modelling and error distribution

\begin{tabular}{|c|c|c|c|}
\hline Bat activity & Model & $\begin{array}{l}\text { Error } \\
\text { distribution }\end{array}$ & Non-linear effect included \\
\hline Abundance & GLMM & Poisson & date of survey ${ }^{2}+$ minutes after sunset ${ }^{2}+$ temperature $^{2}$ \\
\hline Richness & GLMM & Poisson & date of survey ${ }^{2}+$ minutes after sunset ${ }^{2}+$ temperature $^{2}$ \\
\hline CSI & GLMM & Gaussian & date of survey ${ }^{2}+$ minutes after sunset ${ }^{2}+$ temperature $^{2}$ \\
\hline P. pipistrellus & GLMM & Poisson & date of survey ${ }^{2}+$ minutes after sunset ${ }^{2}+$ temperature $^{2}$ \\
\hline P. kuhlii & GLMM & Poisson & date of survey ${ }^{2}+$ minutes after sunset ${ }^{2}+$ temperature $^{2}$ \\
\hline E. serotinus & GLMM & Poisson & date of survey ${ }^{2}+$ minutes after sunset ${ }^{2}+$ temperature $^{2}$ \\
\hline N. leislerii & GLMM & $\begin{array}{l}\text { zero-inflation, } \\
\text { negative binomial }\end{array}$ & \\
\hline N. noctula & GLMM & $\begin{array}{l}\text { zero-inflation, } \\
\text { negative binomial }\end{array}$ & \\
\hline Myotis ssp & GLMM & Quasibinomial & date of survey ${ }^{2}+$ minutes after sunset ${ }^{2}+$ temperature $^{2}$ \\
\hline
\end{tabular}

GLMM were performed using R package lme4 (function glmer, glmer.nb); (2) indicated that we use a quadratic effect to fit nonlinear relationships. We found similar result when nonlinear effects were performed with Generalized Additive Mixed Models (GAMM; Wood, 2006, R package mgcv) to handle nonlinear relationships between the response and some predictive variables; Zero-inflated model were performed using $\mathrm{R}$ package glmmADMB (function glmmadmb); quasibinomial were performed using $\mathrm{R}$ package MASS (function glmmPQL). Choice and validation of model where based on a multi-criteria approach (residual pattern, AIC, pseudo $\mathrm{R}^{2}$ ) following Zuur et al. (2009).

\section{Specific analyses according to the European Union Directives}

Natura 2000 sites include two network: special protection area (SPA, i.e. sites designated under the European Union Directive on the Conservation of Wild Birds) and Sites of Community Importance, (SCI), i.e. sites designated under the European Union's Habitats Directive, also known as the Directive on the Conservation of Natural Habitats and of Wild Fauna and Flora), we performed modelling at three level SPA, SIC and Natura 2000 sites (both together). SPA, SIC modelling were similar than performed in Table 1 and Table 2 
Table S5-3: Partial regression coefficient of the raw Natura 2000 effect for the 3 community metrics and 6 taxa. $\mathrm{P}$-value level of significance associated are ' $* * *$ ' $\mathrm{P}<0.001$; ' $* *$ ' $\mathrm{P}<0.01$; '*' $\mathrm{P}<0.05 ;$; ' $\mathrm{P}<0.1$

\begin{tabular}{lllc}
\hline Bat activity metric & Natura 2000 & \multicolumn{1}{c}{ SICS } & SPA \\
\hline Abundance & $\beta=0.220 \pm 0.035^{* * *}$ & $\beta=0.196 \pm 0.02 * * *$ & $\beta=0.142 \pm 0.040^{* * *}$ \\
Richness & $\beta=0.130 \pm 0.052^{* *}$ & $\beta=0.154 \pm 0.036^{* * *}$ & $\beta=0.070 \pm 0.058$ \\
CSI & $\beta=0.061 \pm 0.020^{* *}$ & $\beta=0.060 \pm 0.013 * * *$ & $\beta=0.066 \pm 0.020^{* *}$ \\
P. pipistrellus & $\beta=0.186 \pm 0.041^{* * *}$ & $\beta=0.097 \pm 0.026 * * *$ & $\beta=0.137 \pm 0.046 * *$ \\
P. kuhlii & $\beta=0.113 \pm 0.128$ & $\beta=0.181 \pm 0.062 * *$ & $\beta=-0.278 \pm 0.153$. \\
E. serotinus & $\beta=0.721 \pm 0.090^{* * *}$ & $\beta=0.346 \pm 0.056 * * *$ & $\beta=0.703 \pm 0.101 * * *$ \\
N. noctula & $\beta=-0.346 \pm 0.387$ & $\beta=-0.105 \pm 0.235$ & $\beta=-0.357 \pm 0.002$ \\
N. leisleri & $\beta=0.272 \pm 0.254$ & $\beta=0.488 \pm 0.159 * *$ & $\beta=0.187 \pm 0.269$ \\
Myotis spp. & $\beta=1.372 \pm 0.209 * * *$ & $\beta=0.694 \pm 0.141 * * *$ & $\beta=1.368 \pm 0.233 * * *$ \\
\hline
\end{tabular}

Table S5-4: Standardized partial regression coefficients from GLMMs model for the proportion of SPA, SACs and Natura 2000 sites for the three community metrics and 6 taxa and at 4 landscape scales considered. P-value level of significance associated are ‘***’ $\mathrm{P}<0.001$; ‘**' $\mathrm{P}<0.01$; ‘*’ $\mathrm{P}<0.05 ;$ ' ’’ $\mathrm{P}<0.1$

\begin{tabular}{|c|c|c|c|c|}
\hline & Scale & Natura 2000 & SICs & $S P A$ \\
\hline \multirow{4}{*}{ Abundance } & 200 & $0.057 * * *$ & $0.045 * * *$ & $0.045 * * *$ \\
\hline & 500 & $0.022 *$ & 0.024 & $0.025 *$ \\
\hline & 700 & $0.028 *$ & 0.023 & $0.036 * *$ \\
\hline & 1000 & 0.030 . & -0.009 & $0.033 * *$ \\
\hline \multirow{4}{*}{ Richness } & 200 & 0.002 & 0.022 & -0.009 \\
\hline & 500 & -0.006 & 0.014 & -0.013 \\
\hline & 700 & -0.009 & 0.010 & -0.016 \\
\hline & 1000 & -0.013 & -0.001 & -0.019 \\
\hline \multirow{4}{*}{ CSI } & 200 & $0.016 * * *$ & $0.026 * * *$ & $0.016 *$ \\
\hline & 500 & $0.013^{*}$ & $0.024 * * *$ & $0.014 *$ \\
\hline & 700 & $0.013 *$ & $0.023 * * *$ & $0.015 *$ \\
\hline & 1000 & 0.011 & $0.022 * * *$ & $0.013 *$ \\
\hline \multirow{4}{*}{ P. pipistrellus } & 200 & $0.038^{* *}$ & -0.002 & $0.032 *$ \\
\hline & 500 & 0.014 & -0.025 & 0.001 \\
\hline & 700 & 0.026 . & -0.017 & 0.021 \\
\hline & 1000 & $0.043 * *$ & -0.006 & $0.038 *$ \\
\hline \multirow{4}{*}{ P. kuhlii } & 200 & 0.069 . & $0.080 *$ & 0.038 \\
\hline & 500 & 0.009 & 0.066 & -0.017 \\
\hline & 700 & -0.027 & 0.051 & 0.005 \\
\hline & 1000 & -0.061 & $-0.098 *$ & -0.031 \\
\hline \multirow{4}{*}{ E. serotinus } & 200 & 0.081 & 0.030 & $0.114 * * *$ \\
\hline & 500 & 0.036 & 0.026 & $0.076 *$ \\
\hline & 700 & 0.026 & 0.021 & 0.057 . \\
\hline & 1000 & 0.029 & 0.034 & 0.051 \\
\hline \multirow{4}{*}{ N. noctula } & 200 & -0.001 & 0.090 & -0.011 \\
\hline & 500 & -0.001 & 0.123 & 0.006 \\
\hline & 700 & -0.038 & 0.114 & -0.023 \\
\hline & 1000 & -0.028 & 0.142 & -0.111 \\
\hline \multirow{4}{*}{ N. leisleri } & 200 & 0.121 & 0.056 & 0.116 \\
\hline & 500 & 0.133 & 0.096 & 0.124 \\
\hline & 700 & 0.117 & 0.121 & 0.077 \\
\hline & 1000 & 0.093 & 0.094 & 0.050 \\
\hline \multirow{4}{*}{ Myotis ssp. } & 200 & $0.234 * * *$ & $0.237 * * *$ & $0.191 * * *$ \\
\hline & 500 & $0.214 * *$ & $0.230 * * *$ & $0.220 * *$ \\
\hline & 700 & $0.225^{* *}$ & $0.280 * * *$ & $0.231 * *$ \\
\hline & 1000 & $0.213 * *$ & $0.229 * *$ & $0.255 * * *$ \\
\hline
\end{tabular}




\section{LITTERATURE CITED}

Zuur, A.F., Ieno, E.N., Walker, N., Saveliev, A.A., Smith, G.M. 2009. Mixed Effects Models and Extensions in Ecology with R. Statistics for Biology and Health, Springer, New York, USA. 574p. 